\title{
Reduction of the Environmental Impact of Electric Field Generated by High Voltage Power Transmission Lines
}

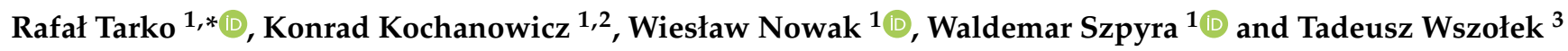 \\ 1 Department of Electrical Engineering and Power Engineering, Faculty of Electrical Engineering, Automatics, \\ Computer Science and Biomedical Engineering, AGH University of Science and Technology, \\ al. Mickiewicza 30, 30-059 Krakow, Poland; kochanowicz@agh.edu.pl (K.K.); \\ wieslaw.nowak@agh.edu.pl (W.N.); wszpyra@agh.edu.pl (W.S.) \\ 2 Eltel Networks Engineering SA, ul. Mazowiecka 21, 30-019 Krakow, Poland \\ 3 Department of Mechanics and Vibroacoustics, Faculty of Mechanical Engineering and Robotics, \\ AGH University of Science and Technology, al. Mickiewicza 30, 30-059 Krakow, Poland; \\ twszolek@agh.edu.pl \\ * Correspondence: rtarko@agh.edu.pl; Tel.: +48-12-617-36-53
}

check for updates

Citation: Tarko, R.; Kochanowicz, K.; Nowak, W.; Szpyra, W.; Wszołek, T. Reduction of the Environmental Impact of Electric Field Generated by High Voltage Power Transmission Lines. Energies 2021, 14, 6388. https://doi.org/10.3390/en14196388

Academic Editor: J. C. Hernandez

Received: 27 July 2021

Accepted: 29 September 2021

Published: 6 October 2021

Publisher's Note: MDPI stays neutral with regard to jurisdictional claims in published maps and institutional affiliations.

Copyright: (c) 2021 by the authors. Licensee MDPI, Basel, Switzerland. This article is an open access article distributed under the terms and conditions of the Creative Commons Attribution (CC BY) license (https:// creativecommons.org/licenses/by/ $4.0 /)$.

\begin{abstract}
The growing interest in the negative environmental impact of overhead power lines of high and extra-high voltage stems from the increasing ecological awareness of societies. Consequently, a number of respective legal restrictions have been issued and actions have been undertaken to reduce this impact, especially in the electric field of the power frequency. The aim of this paper is to analyze the possibilities of reducing the width of electric field influence zones by changing the design parameters of power lines and defining the spatial distribution of its conductors. This analysis was carried out using the developed and experimentally verified models for determining the electric field and audible noise in the power line environment. The computational models were used to analyze the width of the electric field influence zones of $400 \mathrm{kV}$ lines and the noise levels at the borders of these zones. The research focused on single and double circuit $400 \mathrm{kV}$ power lines. It was revealed that a reduction in electric field emissions is accompanied by an increase in noise emission. However, the analyses confirmed that the width of the electric field influence zones can be significantly reduced if the most important design and construction parameters of the line are properly selected. The obtained conclusions are valid not only for $400 \mathrm{kV}$ lines, but also set directions to follow when changing the parameters of high voltage transmission lines of other rated voltages (above $100 \mathrm{kV}$ ).
\end{abstract}

Keywords: right of way; overhead lines; electric field; corona audible noise; modeling; electric field reduction; overhead line design

\section{Introduction}

Limiting the negative environmental impact of high and extra-high voltage overhead power lines is a multi-aspect issue. In practice, activities aimed at reducing these impacts have been carried out since the moment electricity started to be transmitted and distributed-only the directions and priorities are changing in compliance with the current technical, legal, economic and environmental demands. Among the most important ones are the infrastructure corridors, legally distinguished areas on which the power lines can be localized. One of the elements of such a corridor is the power line influence zone, i.e., an area of the property where the property rights are impaired due to restrictions on land use and the need to ensure the safety of people and property.

The basic factor determining the width of the power line influence zone is the emission of the electromagnetic field to the environment. The growing ecological awareness causes that society continues to be more and more interested in the negative environmental impact of high and extra-high voltage overhead power lines. Respective legal restrictions 
are operational, especially when the electric component and magnetic component of an electromagnetic field with power frequency of $50 \mathrm{~Hz}$ or $60 \mathrm{~Hz}$ is involved. The parameters characterizing these elements are electric field strength $(\mathrm{kV} / \mathrm{m})$ and magnetic induction $(\mu \mathrm{T})$. In 1998, the International Commission on Non-Ionizing Radiation Protection (ICNIRP) issued guidelines [1], which set the limit values for these components at $E=5 \mathrm{kV} / \mathrm{m}$ and $B=100 \mu \mathrm{T}$. These values have been adopted in most countries and are also recommended by the European Union, as stated in the respective document of 1999 [2]. In spite of this, some countries have local regulations [3] in which the permissible values of electric and magnetic fields can be both higher/lower than values specified in the international documents. The requirements imposed by countries listed in Table 1 exemplify this trend. It should be also mentioned that in 2010, ICNIRP published new guidelines [4] in which the permissible value of magnetic field induction was increased from $100 \mu \mathrm{T}$ to $160 \mu \mathrm{T}$.

Table 1. Selected reference levels or exposure limits for the general public for electromagnetic fields in inhabited areas (prepared on the basis [3]).

\begin{tabular}{ccc}
\hline & \multicolumn{2}{c}{$\mathbf{5 0 ~ H z}$} \\
\cline { 2 - 3 } Country & $\begin{array}{c}\text { Electric Field Strength } \\
(\mathbf{k V / m})\end{array}$ & $\begin{array}{c}\text { Magnetic Flux Density } \\
(\boldsymbol{\mu} \mathbf{T})\end{array}$ \\
\hline China & 4 & 100 \\
Croatia & 2 & 40 \\
Czech Republic & 2 & 200 \\
Japan & 3 & 200 \\
Poland & 1 & 75 \\
Russia & 0.5 & 5 \\
Slovenia & 0.5 & 10 \\
United Kingdom & 9 & 360 \\
\hline
\end{tabular}

The magnitude of electromagnetic field emission is affected by many factors, among which rated voltage and line current load are of primary importance. The second, equally important factor, is the spatial distribution of phase wires and earth wires. This factor is conditioned by the shape of the applied supporting structures and insulator chains. The range of the electromagnetic impact zone results from the spatial distribution of the electric field and magnetic field and is limited by the location for which the assumed permissible values were obtained. Figure 1 presents an example of the electric field and magnetic field in the cross-section of a $400 \mathrm{kV}$ double circuit line. In the example, the assumption of phase voltage symmetry was made, which is complied with in high and extra-high voltage networks. In addition, the load phase symmetry of each circuit was assumed.

These images visualize isolines for reference electric field strengths of $5 \mathrm{kV} / \mathrm{m}$ and $1 \mathrm{kV} / \mathrm{m}$, and magnetic field isolines for reference magnetic induction values: $160 \mu \mathrm{T}$, $100 \mu \mathrm{T}$ and $75 \mu \mathrm{T}$. These isolines were determined for the highest operating voltage of a $420 \mathrm{kV}$ line, the highest power line current-carrying capacity of the line of $2500 \mathrm{~A}$ and the shortest distance of the phase wires from the ground of $11.0 \mathrm{~m}$. The reference values of magnetic induction $B=75 \div 160 \mu \mathrm{T}$ are contained in the space where the electric field strength $E>5 \mathrm{kV} / \mathrm{m}$, as shown in Figure 1. For this reason, the width of the electromagnetic influence zone of a power line is determined by the electric component of the electromagnetic field-widths $S_{E 5}$ and $S_{E 1}$ in Figure 1. This statement is true not only for the images shown here, but can be generalized for other overhead power line structures as well.

The electric field of overhead power lines is strongly non-uniform, with the highest values occurring at the wire surface. If these values exceed the air ionization onset voltage gradient, the phenomenon of the corona effect will occur in the vicinity of wires. One of the main factors determining corona formation and its intensity is the design of phase wires. 
Reduction of the electric field strength on the surface of the phase wires is achieved by using wire conductor bundles (Figure 2). The bundle usually consists of 2 to 4 subconductors.
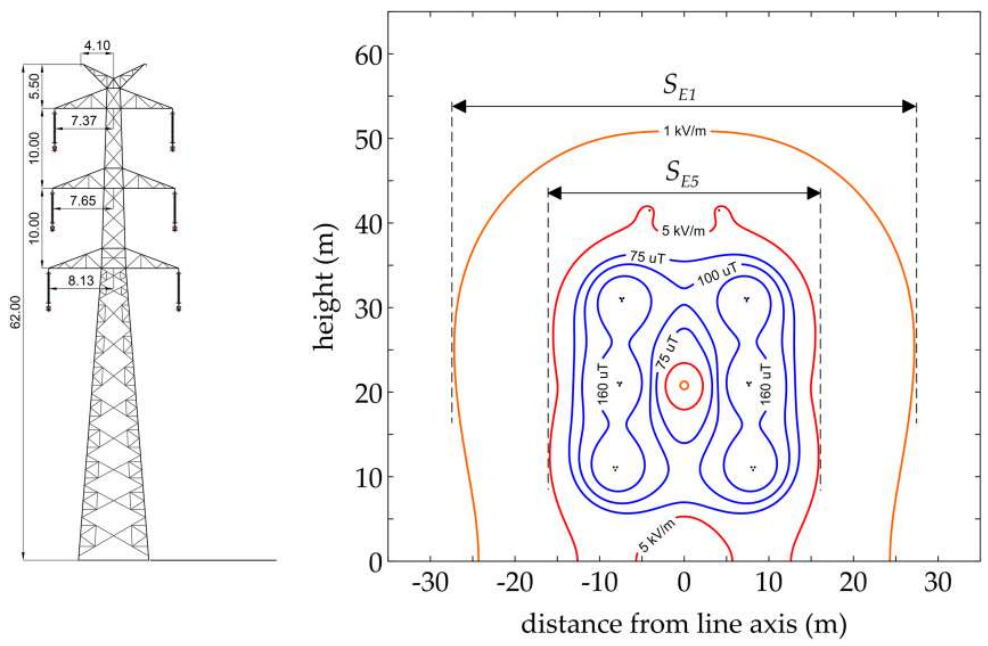

Figure 1. Exemplary images of electric and magnetic fields and widths of impact zones in the crosssection of a double circuit $400 \mathrm{kV}$ line $S_{E 5}, S_{E 1}$-electric field exposure zone widths for admissible values $5 \mathrm{kV} / \mathrm{m}$ and $1 \mathrm{kV} / \mathrm{m}$ (authors' research).

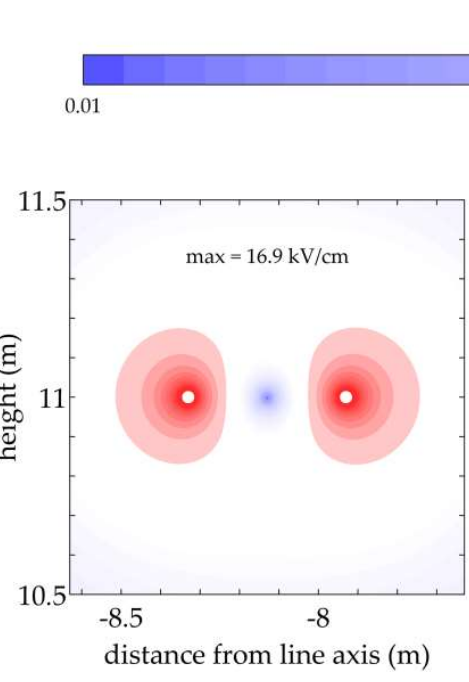

(a)

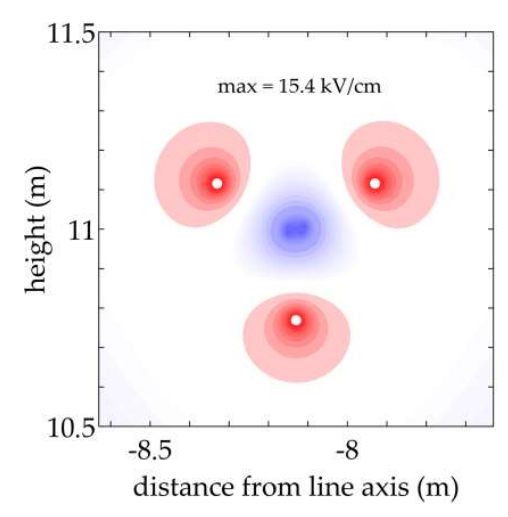

(b)

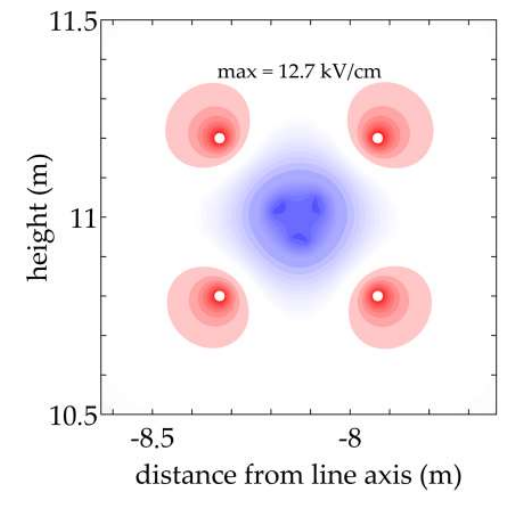

(c)

Figure 2. Exemplary images of electric field strength in the vicinity of a phase wire of a double circuit $400 \mathrm{kV}$ line for a different number $N$ of conductors in a bundle: (a) $N=2$; (b) $N=3$; (c) $N=4$ (authors' research).

One of the negative corona effects is the audible noise. It significantly differs from the noise generated by other sources, e.g., transportation or industrial sources, because it strongly depends on such random causes as weather conditions or the surface condition of the line wires. The intensity of corona $A$-weighted audible noise level (Figure 3 ) in fair weather at a distance of $30 \mathrm{~m}$ from the lateral conductor, is about $30 \div 40 \mathrm{~dB}$, while on rainy and humid days it may reach up to $55 \mathrm{~dB}$.

International documents $[5,6]$ on the negative environmental impact of noise do not mention power lines as a source. Therefore, general criteria specified in document [7] have been adopted for assessing the environmental effect of noise generated by power lines. In practice, the following impact assessment indicators are used: general indicator of annoyance day-evening-night $L_{d e n}$ and detailed indicator of noise annoyance (sleep distur- 
bances) at night $L_{\text {night }}$. The values of these indicators have been determined $4 \mathrm{~m}$ above the ground level.

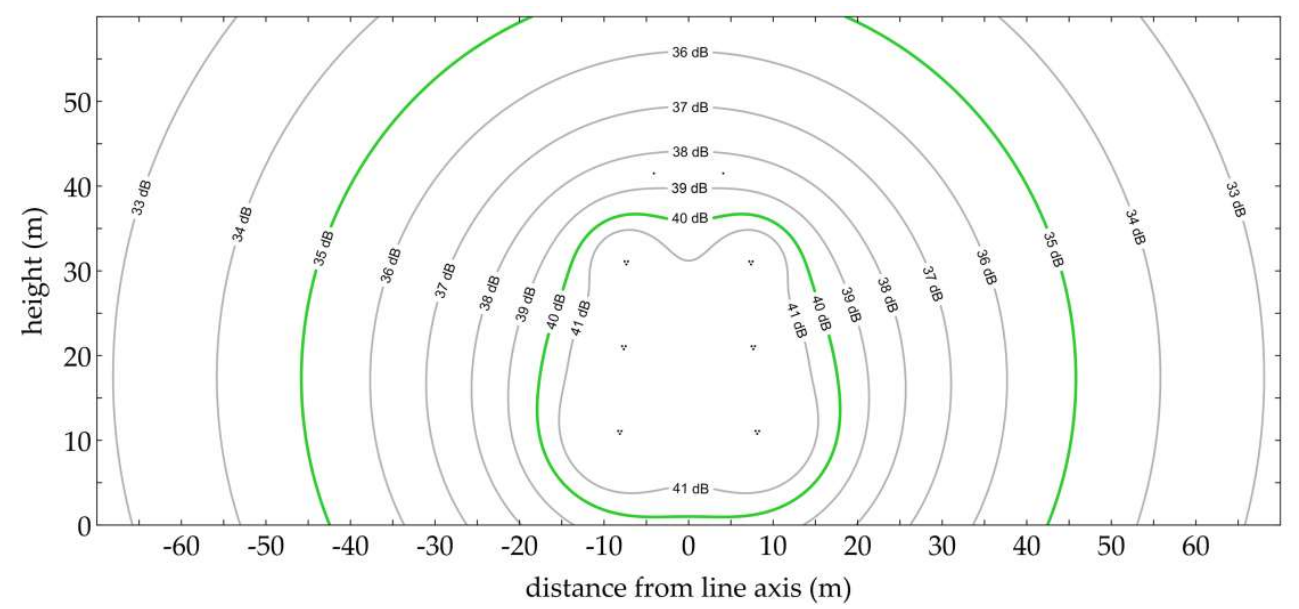

Figure 3. Exemplary image of $A$-weighted corona audible noise level (in fair weather) in a crosssection of a $400 \mathrm{kV}$ double circuit line (authors' research).

Document [6] provides recommendations for the highest values of these indicators, and which, depending on the source of noise, are: $L_{d e n}$ from $54 \mathrm{~dB}$ to $45 \mathrm{~dB}$ and $L_{\text {night }}$ from $45 \mathrm{~dB}$ to $40 \mathrm{~dB}$. Similar recommendations are included in document [5], in which $L_{A e q}$ of $50 \div 55 \mathrm{~dB}$ during the day, and $5 \div 10 \mathrm{~dB}$ lower values for the night were assumed as annoying noise values. It should be noted, however, that predicting power line noise and relating the obtained values to the quoted limits is often problematic due to the strong impact of weather conditions on the level of generated noise $[8,9]$.

Authors of this paper study the impact of power line design parameters determining the spatial arrangement of its wires on the width of electric field impact zones $S_{E 5}$ and $S_{E 1}$. It should be highlighted the originality of the authors' research based on the complementary consideration of the electric field and the acoustic emission in the vicinity of the line. Such an approach has not been presented in the subject literature till now. In addition, it should be noted that the analysis was performed using developed programs, and experimentally verified authors models presented in Section 2. These models was used to determine the electric field in the vicinity of the line and on the conductor surfaces, as well as the noise generated by the line. The objects and scope of the study and the construction parameters of single and double circuit lines are described and specified in Section 3. The range of possible changes in the values, resulting from the applied standards and technical feasibility, was determined for these parameters. Section 4 presents the results of investigations of impact of the considered parameters on the widths of zones $S_{E 5}$ and $S_{E 1}$ of selected single and double circuit $400 \mathrm{kV}$ lines, as well as the impact on noise levels $L_{A 5}$ and $L_{A 1}$ at the border of zones $S_{E 5}$ and $S_{E 1}$. The results presented in the article can be used as a basis for selecting the best design solution for the line in terms of minimizing the negative environmental impact. They also suggest possible directions of design changes for lines of other voltages. The results of the analysis presented in the article have allowed us to identify the crucial construction parameters of the line, which is important for the width of the electric field exposure zones. The research has shown that in some cases, it is possible to reduce the width of the zones by up to $50 \%$.

\section{Models for the Analysis of Electric Field and Noise Emission of High-Voltage Power Lines}

\subsection{Electric Field Model}

The space in the vicinity of high voltage overhead power lines is the electromagnetic field area. At the network frequency $f=50 \mathrm{~Hz}$, the electric component of this field can be considered independently of the magnetic one. Another simplification is the application 
of the electrostatic laws to the analysis of the electric field [10]. In general, the basis for calculations are the equations relating the electric field strength $\mathbf{E}$ with the electric charges $Q$ accumulated on the elements of the considered system and with their spatial distribution. When writing these equations for the electric field in the vicinity of overhead power lines, the charge simulation method is of particular importance [11-15]. In this method, the actual distribution of charges on the wire surfaces with known potential values are replaced by a set of fictitious charges, so that the electric field induced by these charges is identical with the real one. The simulation charges are assumed to be the geometrically simplest elements, including, but not limited to, line charges, uniformly distributed along a straight line section. Besides the simulated charge method, the finite element method is also used to calculate the field distribution around overhead lines [12,16].

Line models for electric field calculations can be created in both 2-D and 3-D spaces [17]. Figure 4 shows how the wires of an example span (Figure 4a) and the support structure of a double circuit $400 \mathrm{kV}$ line (Figure $4 \mathrm{~b}$ ) are modelled by authors in a 3-D space.

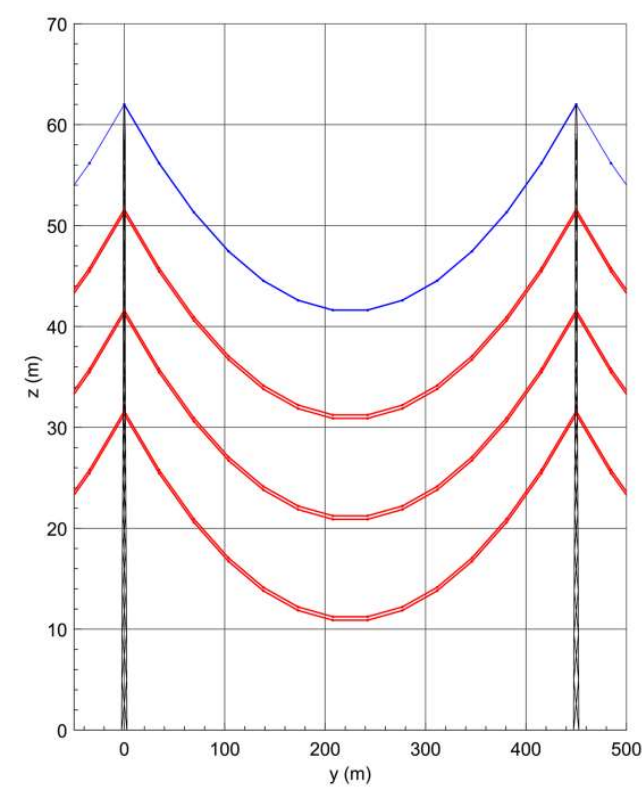

(a)

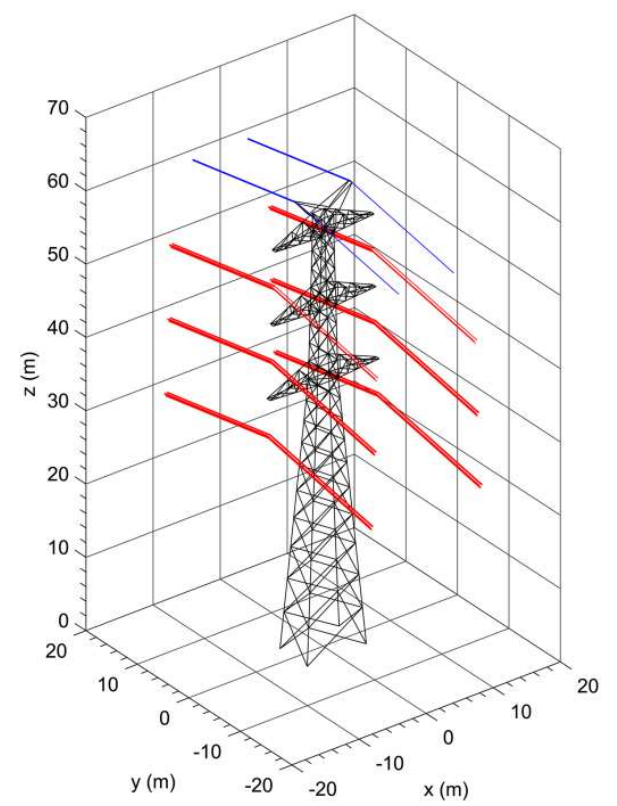

(b)

Figure 4. Representation of an exemplary double circuit $400 \mathrm{kV}$ line for the charge simulation method: (a) span wires; (b) support structure.

The presented line is equipped with six phase wires in the form of three-conductor bundles (18 conductors in total) and two earth wires. The shape of the catenary curve of each of the wires of the line was approximated by 13 rectilinear sections. The supporting structure was approximated by a set of 352 sections representing profiles making up the lattice tower body. The potentials of sections approximating the phase wires are equal to the phase voltages of the line whereas the potentials of sections approximating earth wires and the support structure are equal to zero.

The calculations are performed with the mirror image method and the potential superposition principle. It was assumed that the earth is a perfectly conducting smooth surface, however, in the literature there are also presented models for the complex terrains under power lines [18]. Based on the above assumptions the following equations can be written for a set of $\mathrm{n}$ charges distributed uniformly on the approximating sections (Figure 4):

$$
v_{i}(t)=\sqrt{2} U_{i} \sin \left(2 \pi f t+\varphi_{i}\right)=\sum_{j=1}^{n}\left(\alpha_{i j}-\beta_{i j}\right) q_{j}(t), \quad i=1, \ldots, n,
$$


where: $v_{i}(t)$-instantaneous potential of the $i$-th approximating section, $U_{i}$-rms value of phase voltage of the $i$-th approximating section, $f$-voltage frequency, $\varphi_{i}$-voltage phase, $q_{j}(t)$ - charge of the $j$-th approximating section, $\alpha_{i j}$-potential coefficient between the $i$-th and $j$-th sections, $\beta_{i j}$-potential coefficient between the $i$-th section and the mirror image of the $j$-th section.

In Equation (1), the potentials $v_{i}(t)$ of the approximating sections are known, whereas the potential coefficients $\alpha_{i j}$ and $\beta_{i j}$ are calculated from the geometry of these sections in the assumed coordinate system based on the following relations:

$$
\alpha_{i j} \text { or } \beta_{i j}=\frac{1}{4 \pi \varepsilon_{0} l_{i} l_{j}} \int_{l_{i}} \int_{l_{j}} \frac{d l_{i} \cdot d l_{j}}{r},
$$

where: $r$-distance between elements $d l_{i}$ and $d l_{j}$ of wires which are $l_{i}$ and $l_{j}$ long. Unknown charges $q(t)$ are determined by solving Equation (1). Charges $q_{i}(t)$-linear combinations of harmonic functions with the same frequency $\omega$, are harmonic functions defined as:

$$
q_{i}(t)=Q_{i} \sin \left(\omega t+\Theta_{i}\right), \quad i=1, \ldots, n,
$$

Electric field potential $v_{B}$ at point $B(x, y, z)$ in the vicinity of a power line can be determined based on section charges (3) and potential superposition principle:

$$
v_{B}(x, y, z, t)=\sum_{i=1}^{n}\left[\alpha_{B i}(x, y, z)-\beta_{B i}(x, y, z)\right] \cdot q_{i}(t),
$$

where $\alpha_{B i}\left(\beta_{B i}\right)$ is a potential coefficient between point $B$ and the $i$-th section (mirror image of the section). This coefficient directly stems from Equation (9):

$$
\alpha_{i j}\left(\beta_{i j}\right)=\frac{1}{4 \pi \varepsilon_{0} l_{i}} \int_{l_{i}} \frac{d l_{i}}{r},
$$

and $r$ is a distance between element $d l_{i}$ of the $i$-th wire with length $l_{i}$, and point $B$.

The vector of electric field strength at point $B$ is a potential gradient (4):

$$
\mathbf{E}=-\operatorname{grad} v_{B}(x, y, z, t),
$$

The following value at point $B$ is assumed while assessing the environmental electric field impact:

$$
E_{B}(x, y, z)=\frac{\max _{t}\{E(x, y, z, t)\}}{\sqrt{2}},
$$

Based on the above assumptions and Equations (1)-(7), an appropriate numerical calculation agorithms were developed, implemented in the Matlab software, and used for the research presented in this paper.

\subsection{Corona-Generated Audible Noise Model}

The spectrum of the corona noise signal is a broadband noise spectrum with a random content of tonal components, i.e., higher harmonics of doubled power frequency.

The main energy of the spectrum is contained in the noise part. This is more apparent when the noise signal is passed through a filter with a standardized $A$ ( $A$-weighted) frequency curve [19] (Figure 5a), whose highest values are found in the frequency range from $2 \mathrm{kHz}$ to $4 \mathrm{kHz}$, corresponding to the noise part of the corona audible noise signal spectrum. The $A$-weighted noise level corresponds to a loudness level of 40 phonons, and the $A$-weighted sound level $\left(L_{A}\right)$ is accepted as the best approximation of the human auditory experience up to $70 \mathrm{~dB}$ and is a commonly used indicator for assessing noise annoyance. Figure $5 \mathrm{~b}$ shows a typical unweighted and $A$-weighted noise signal spectrum 
from an intense corona in rainy conditions, as well as the ambient noise spectrum during night hours.

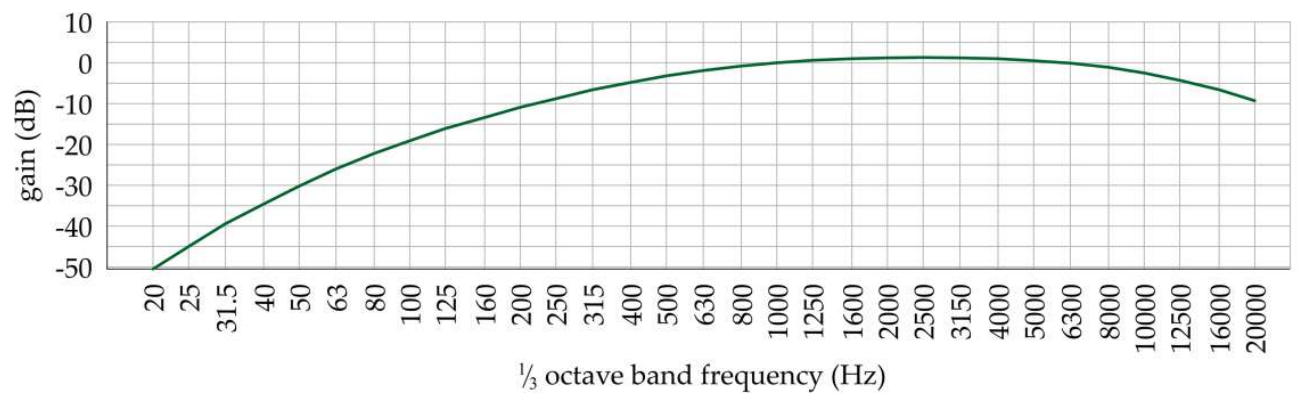

(a)

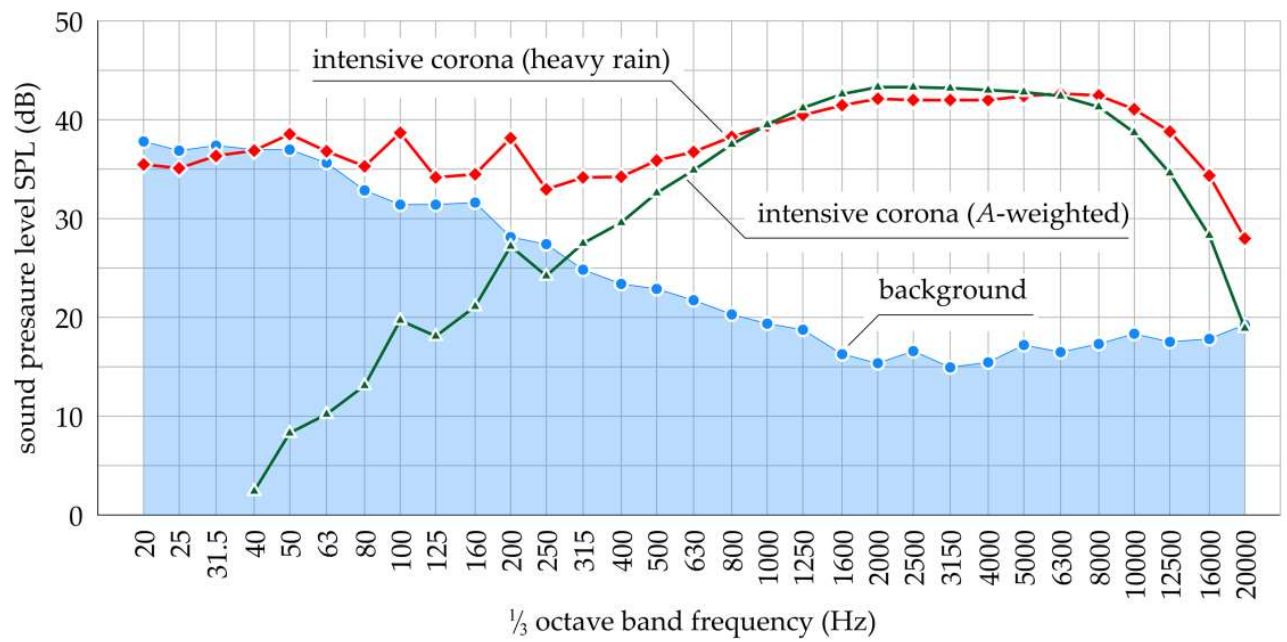

(b)

Figure 5. Typical spectrum of noise signal during intense corona and spectrum of noise background (own research): (a) standardized frequency $A$-weighted curve; (b) unweighted and $A$-weighted spectrum of corona noise signal (authors' research).

In view of the above characteristics of the noise signal spectrum, the existing corona audible noise models refer to an $A$-weighted level dominated by the noise component, while the tonal components (if present) can be taken into account when determining the rating levels, e.g., by adding the adjustment level to $L_{\text {Aeq }}[20,21]$.

The general form of the noise model incorporates factors affecting the generated sound power level, as well as the distance from the observation point. For a power transmission line, the general model assumes the following form:

$$
L_{A}=k_{1} \cdot f_{1}\left(E, E_{0}\right)+k_{2} \cdot f_{2}(n)+k_{3} \cdot f_{3}(r)+k_{4} \cdot f_{4}(l)+L_{0},
$$

where: $L_{A}$-predicted $A$-weighted $S P L(\mathrm{~dB})$ at a distance $l, E$-maximal electric field strength $(\mathrm{kV} / \mathrm{cm})$ on the wire surface, $E_{0}$ - electric field strength $(\mathrm{kV} / \mathrm{cm})$ on the wire surface, above which corona takes place, $n$-number of conductors in the bundle, $r$-radius $(\mathrm{cm})$ of bundle component wire, $l$-distance $(\mathrm{m})$ between observation point $B$ and the wire, $L_{0}$-noise reference level (dB).

The above form has been adopted to almost all known line acoustic noise models, although they differ in the values of coefficients and sometimes in the forms of particular functions [22].

To determine the level of audible noise generated by extra-high voltage power lines, it is necessary to know the highest values of electric field strength $E$ on the surface of the wires [23-25]. These values are determined using the electric field model presented in Section 2.1. For this purpose, $K$ points are selected on the surface of each of the wires 
and are uniformly distributed around their perimeter, $\mathrm{m}$ (e.g., $K=360)$. At these points the electric field strength is calculated. The highest strength value is determined for the surface of a given wire. In the case of a bundle component wire, the averaged maximum values on the surfaces of the component conductors is taken when determining the sound pressure level.

Electric field strength $E_{0}(\mathrm{kV} / \mathrm{cm})$, above which the corona effect takes place, is determined by Peek's empirical formula [25]:

$$
E_{0}=21.2 \delta m_{1} m_{2}\left(1+\frac{0.301}{\sqrt{\delta r}}\right),
$$

where: $\delta$-relative density of air, $m_{1}$ - coefficient depending on the condition of the wire and atmospheric conditions $\left(m_{1}=1\right.$-for a smooth and dry surface; $m_{1}=0.6 \div 0.8$-for a wet surface; $m_{1}=0.3 \div 0.6$-water drops, icicles or major impurities on the surface; $m_{1}=0.25$ - heavy rain), $m_{2}$-coefficient accounting for weather conditions equal to 0.8 for rain, $r$-wire radius $(\mathrm{cm})$.

Based on own studies of a $400 \mathrm{kV}$ line, noise models were developed for establishing sound pressure levels $L_{A w(r)}$ and $L_{A w(n r)}$ during rain and rain-free conditions, respectively. The general form of these models assumes the following form:

$$
\begin{gathered}
L_{A w(r)}=10 \log \left\{E^{8.5}\left[1-\exp \left(-0.11 \delta_{r}\left(E-E_{0}\right)^{4 / 3}\right)^{1.8}\right]\right\}, \\
L_{A w(n r)}=10 \log \left\{E^{8.5}\left[1-\exp \left(-0.04 / m_{s}\left(E-E_{0}\right)^{4 / 3}\right)^{3.7}\right]\right\},
\end{gathered}
$$

where: $\delta_{r}$-rain fall $(\mathrm{mm} / \mathrm{h}), m_{s}$-coefficient depending on the wire condition $\left(m_{s} \in<0.4\right.$; $1.0>, m_{s}=1 —$ smooth and undamaged wire, $m_{s}=0.4$-soiled wire and / or with a damaged surface.

The total noise emission level $L_{A i}$ from the $i$-th wire of the line is expressed with the formula:

$$
\begin{gathered}
L_{A i(r)}=L_{A w(r)}+\Delta L_{n s}+\Delta L_{r}+\Delta l-L_{0}, \\
L_{A i(n r)}=L_{A w(n r)}+\Delta L_{n s}+\Delta L_{r}+\Delta l-L_{0},
\end{gathered}
$$

where: $L_{0}$-reference level of $63 \mathrm{~dB}$,

$$
\begin{gathered}
\Delta L_{n s}=10 \log (n), \\
\Delta L_{r}=45 \log (r), \\
\Delta l=-10 \log (l),
\end{gathered}
$$

The summary noise emission level $L_{A}$ from $k$ phase wires is calculated with the relation:

$$
L_{A}=10 \log \sum_{i=1}^{k} 10^{0.1 L_{A i}},
$$

Based on the above assumptions and Equations (8)-(17), appropriate numerical calculation algorithms were developed, implemented in the Matlab software and used for the research presented in this paper.

\subsection{Experimental Validation of Models}

In order to verify the electric field model presented in Section 2.1, measurements were performed under a double circuit $220 \mathrm{kV}$ line shown in Figure 6a. They showed a good congruence of measured and calculated electric field strength values. This is confirmed by Figure $6 \mathrm{~b}$. It shows a comparison of the measured and calculated distribution in the cross-section of the line at a $2 \mathrm{~m}$ height. The conducted research proved the validity of the 
assumptions made and also confirmed that this model can be used in further analyses on the reduction of electric field impact zones of overhead power lines.

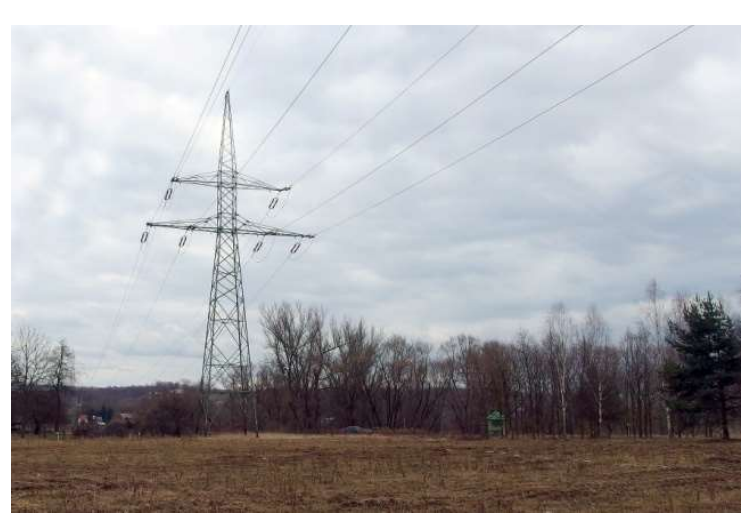

(a)

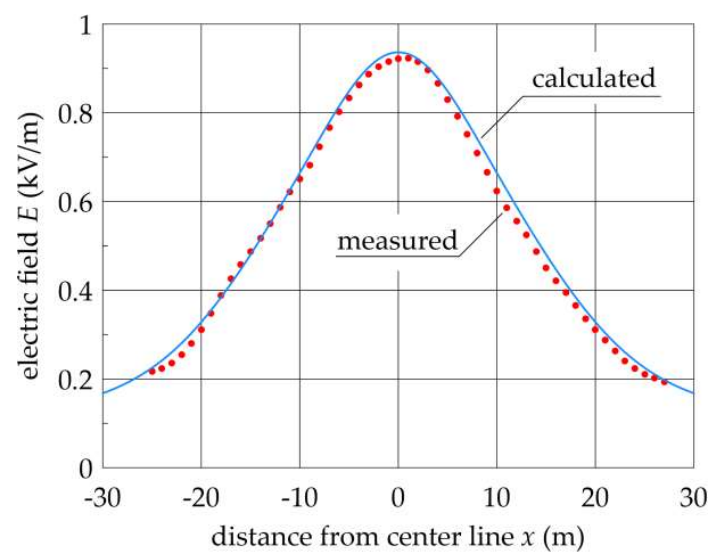

(b)

Figure 6. Measurement verification of the electric field model under the double circuit $220 \mathrm{kV}$ line: (a) a fragment of the span in the place of measurements; (b) comparison of the measured and calculated distribution in the cross-section of the line at a $2 \mathrm{~m}$ height.

To verify the power line corona audible noise model presented in Section 2.2, measurements were conducted in the vicinity of a double circuit $400 \mathrm{kV}$ line with $N=2$ bundle wires (Figure $7 \mathrm{a}$ ) and in the vicinity of a double circuit $400 \mathrm{kV}$ line with $N=3$ bundle wires (Figure $7 \mathrm{c}$ ). Figure $7 \mathrm{~b}, \mathrm{~d}$ compares the measured results during rain with the results obtained from model calculations.

A monitoring station SVAN210 with a GRAS microphone 40 AE was used for the verification of measurements. Meteorological measurements were performed with a WatchDog 2900 station and Vaisala Airmar Station PB100. Acoustic signals at both stations were recorded in $1 / 3$ octave bands ranging from $10 \mathrm{~Hz}$ to $20 \mathrm{kHz}$, with a time resolution of $10 \mathrm{~s}$. Measurements were conducted over a period of approximately one and a half days (35 h), and the measurement values were averaged with a 15-min resolution. The comparative analyses of the measured and calculated signal were made with level $L_{A(90)}$, i.e., $A$-weighted statistical (percentiles) $L_{90}$ level (the level exceeded for $90 \%$ of the time).

The verification of the model calculations lied in using actual (measured) values of rainfall intensity and carrying out model calculations for them. The obtained results are given in Figure $7 \mathrm{~b}, \mathrm{~d}$. The output of calculations was performed according to the proposed corona audible noise model, which coincides with the measured results in the rainfall conditions.

In analyzed cases, the average difference in the whole measurement window (during rain) is $0.1 \mathrm{~dB}$ (Figure $7 \mathrm{~b}$ ) and $0.2 \mathrm{~dB}$ (Figure $7 \mathrm{~d}$ ). For the line with $N=2$ bundle, the measured value of $L_{A(90)}$ level during rain (from 12:00 to $15: 30$ the next day) is $50.9 \mathrm{~dB}$ and the calculated value during this time interval $L_{A(\text { model })}=50.8 \mathrm{~dB}$. For the line with $N=3$ bundle, the measured value of $L_{A(90)}$ level during rainfall is $43.9 \mathrm{~dB}$, and the calculated value during this time interval $L_{A(\text { model })}=43.7 \mathrm{~dB}$. For the entire measurement interval shown in Figure 7d, which also includes rain intervals, the measured $L_{A(90)}$ level is $41.8 \mathrm{~dB}$ and the model calculated value $L_{A(\text { model })}$ for this time equals to $38.9 \mathrm{~dB}$.

The values in individual 15-min windows vary much more in Figure $7 \mathrm{~b}$ even $4-5 \mathrm{~dB}$, and the standard deviation of the difference between these levels is $1.95 \mathrm{~dB}$. In general, the calculated results for this case are only slightly different from the measured results, mainly due to the continuous rainfall and the noise associated with it. The measurement window of the line with the $N=3$ bundle is characterized by a high variability of rainfall intensity, and consequently variability of the accompanying noise emission (Figure 7d). The average difference over the entire measurement window (with moments of no rain or very little rain) is $1.9 \mathrm{~dB}$. However, in the part of the measurement window between 
3:00 and 5:00, when the rainfall was more uniform, the results of model calculations $\left(L_{A(\text { model })}=45.4 \mathrm{~dB}\right)$ practically do not differ from the measured results $\left(L_{A(90)}=45.3 \mathrm{~dB}\right)$. Furthermore, it should be noted that during the short intervals between rainfall occurrences, the wires stay wet, resulting in higher noise emissions than model calculations would predict. This can be seen in the 7:30 and 1:30 time interval (Figure 7d). The maximum differences between the measured and calculated values in the 15-min windows may exceed $8 \mathrm{~dB}$, with a standard deviation of $2.6 \mathrm{~dB}$. Such a discrepancy of the results mainly stems from the high inertia of the corona effect. This is especially evident in the time between 1:30 and 9:00 the next day (Figure 7d), where the measured results are much higher than the calculated values. This is caused by the fact that the model does not take into account the inertia of the corona effect when rainfall stops. Model calculations in the case of precipitation disappearance are usually performed as for dry wires. In reality, however, the wires are wet for a long period of time and the corona with its accompanying phenomena (though less intense) still takes place. However, the problem of inertia is negligible in the noise prediction practice. The calculations make use of average values or possibly the maximum precipitation value, as the maximum sound generation due to corona occurs during the rain.

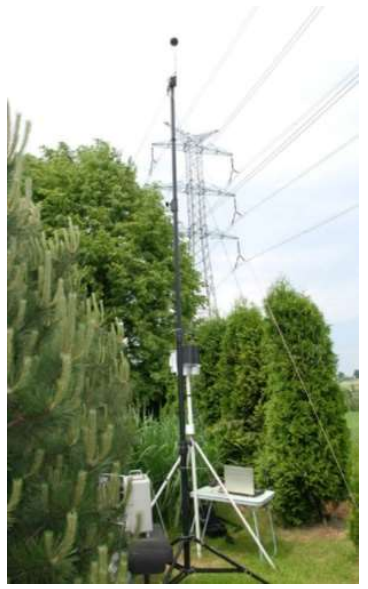

(a)

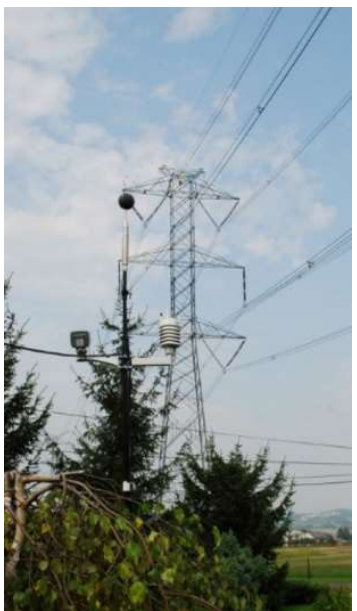

(c)

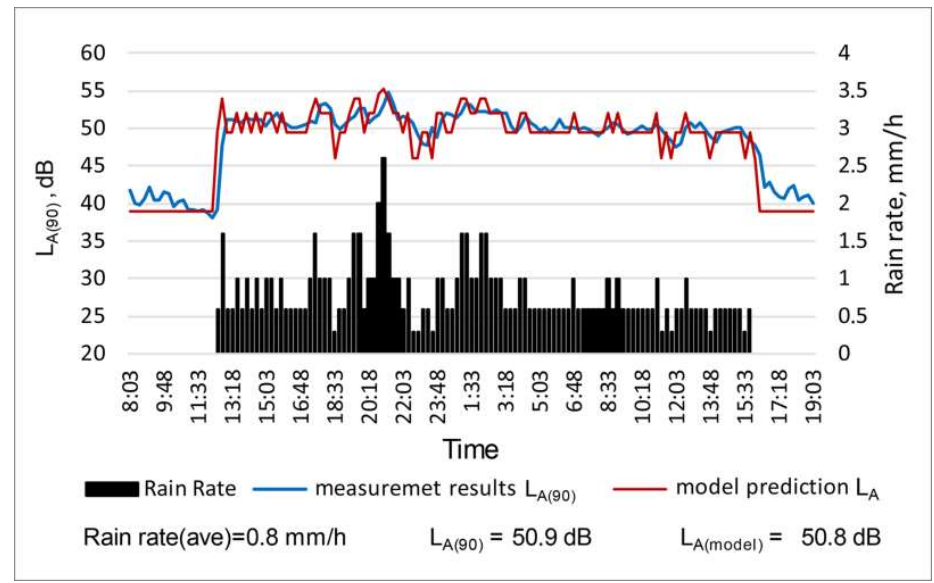

(b)

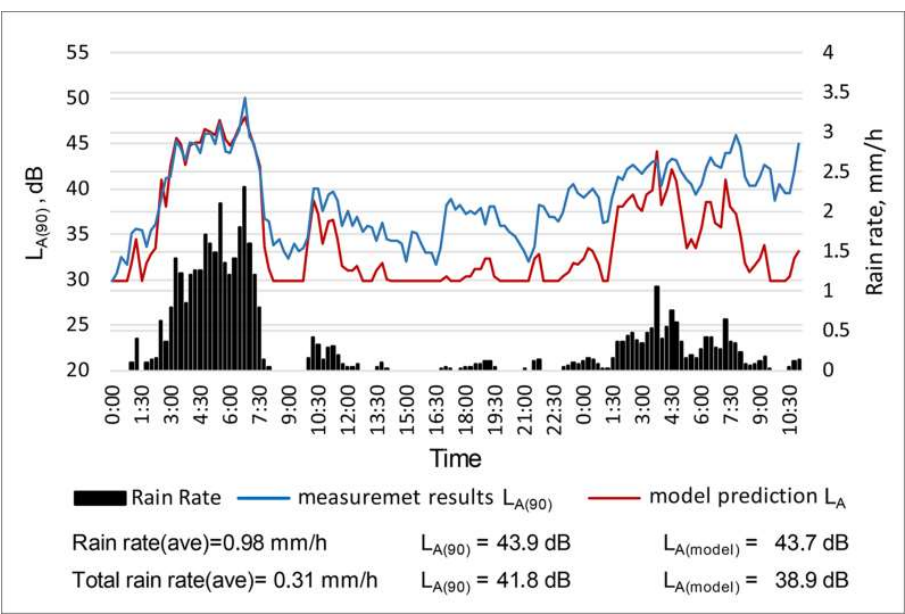

(d)

Figure 7. Compared results of noise measurement $\left(L_{A(90)}\right.$ level) and model calculations $\left(L_{A \text { (model })}\right.$ level) in the vicinity of double circuit $400 \mathrm{kV}$ lines: $(\mathbf{a}, \mathbf{b})$ with $N=2$ bundled wires; (c,d) with $N=3$ bundled wires. 


\section{Subject and Scope of Research}

The computational models presented in Section 2 were used for analyzing zone widths $S_{E 5}$ and $S_{E 1}$ of the electric field impact of $400 \mathrm{kV}$ lines, and studying noise levels $L_{A 5}$ and $L_{A 1}$ at the borders of zones $S_{E 5}$ and $S_{E 1}$. The tests were performed for single and double circuit $400 \mathrm{kV}$ power lines, whose symmetrical wire configurations and arrays are shown in Figure 8. The analysis assumes symmetry of the phase voltages.

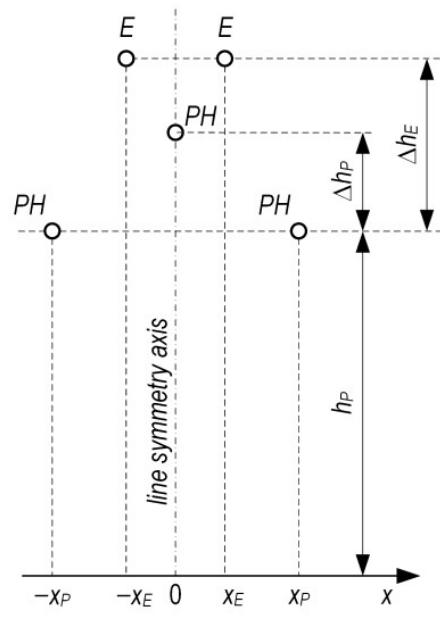

(a)

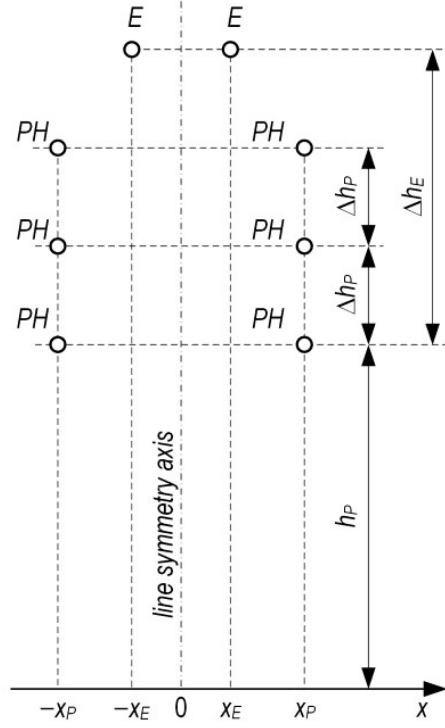

(b)

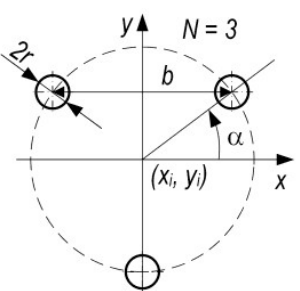

(c)

Figure 8. Analyzed parameters of $400 \mathrm{kV}$ line: (a) single circuit line; (b) double circuit line; (c) phase wire.

Structural parameters (Table 2), which are significant for the zone widths $S_{E 1}$ and $S_{E 5}$, were indicated for the feasibility analysis of electric field impact reduction. The purpose of this study was to determine the effect of changes in these parameters on the possibility of reducing $S_{E 1}$ and $S_{E 5}$ zones.

Table 2. Analyzed design parameters of the overhead power line.

\begin{tabular}{cl}
\hline Symbol & \multicolumn{1}{c}{ Parameter Description } \\
\hline$x_{P}$ & $\begin{array}{l}\text { outer phase conductor horizontal distance to axis of the single circuit line } \\
\text { outer phase conductor horizontal distance to axis of the double circuit line }\end{array}$ \\
\hline$h_{P}$ & conductor height at tower \\
\hline$\Delta h_{P}$ & $\begin{array}{l}\text { inner phase conductor horizontal distance to outer phase conductor } \\
\text { phase-to-phase vertical distance in the double circuit line }\end{array}$ \\
\hline$x_{E}$ & earth wire horizontal distance to axis of the double circuit line \\
\hline$\Delta h_{E}$ & earth wire vertical distance to lowest conductor \\
\hline$f_{P}$ & conductor sag \\
\hline$f_{E}$ & earth wire sag \\
\hline$N$ & number of subconductors per bundle \\
\hline$b$ & subconductor distance within a bundle
\end{tabular}

The parameters shown in Table 2 can be classified into three groups. The first group includes parameters $x_{P}, h_{P}$, and $h_{P}$, which determine the geometric arrangement of phase wires in the line's cross-section. Together with parameter $f_{P}$ they form a system that gives full information about the location of phase wires in a given line's cross-section. The values of $h_{P}$ and $f_{P}$ parameters are closely related to the required distance from the ground. 
The second group includes parameters $x_{E}$ and $h_{E}$, which together with $f_{E}$ determine the place of the earth wires. The third group consists of $N$ and $b$ parameters that characterize the structure of the bundled phase conductors (Figure 7c).

The range in which these parameters oscillate results from the normative requirements [26] ensuring safety insulation clearances determined by the rated voltage, overvoltage and environmental conditions. Permissible ranges and typical values of parameters of the $400 \mathrm{kV}$ line are given in Tables 3 and 4 .

Table 3. Admissible ranges and typical values of analyzed parameters of support structures.

\begin{tabular}{ccccc}
\hline & \multicolumn{2}{c}{ Single Circuit Lines } & \multicolumn{2}{c}{ Double Circuit Lines } \\
\cline { 2 - 5 } Line Parameter & Range & $\begin{array}{c}\text { Typical } \\
\text { Example }\end{array}$ & Range & $\begin{array}{c}\text { Typical } \\
\text { Example }\end{array}$ \\
\hline$x_{P}(\mathrm{~m})$ & $6 \div 12$ & 10.3 & $4 \div 9$ & 8.45 \\
\hline$h_{P}(\mathrm{~m})$ & $0 \div 2$ & Depends on conductor sag & \\
\hline$\Delta h_{P}(\mathrm{~m})$ & $5 \div 12$ & 0 & $6 \div 10$ & 9.2 \\
\hline$x_{E}(\mathrm{~m})$ & $6.5 \div 15$ & 7.5 & $0 \div 8.5$ & 10 \\
\hline$\Delta h_{E}(\mathrm{~m})$ & & 7 & 10 & \\
\hline$f_{P}(\mathrm{~m})$ & & Depends on conductors design and tension \\
\hline$f_{E}(\mathrm{~m})$ & & Depends on conductors design and tension \\
\hline
\end{tabular}

Table 4. Admissible ranges and typical values of analyzed conductor bundle parameters.

\begin{tabular}{ccc}
\hline Conductor Parameter & Range & Typical Example \\
\hline$N$ & $2 \div 4$ & $2 \div 3$ \\
\hline$b(\mathrm{~mm})$ & $350 \div 500$ & 400 \\
\hline
\end{tabular}

Figure 9 shows the schemes of the single and double circuit $400 \mathrm{kV}$ line towers adopted for the study. The indicated dimensions can be treated as typical for this level of rated voltage.

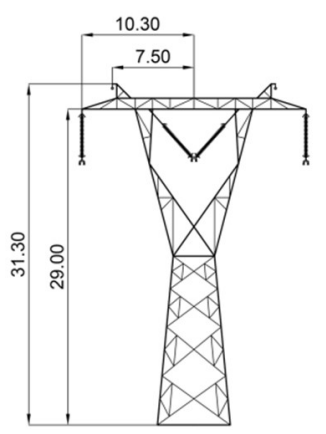

(a)

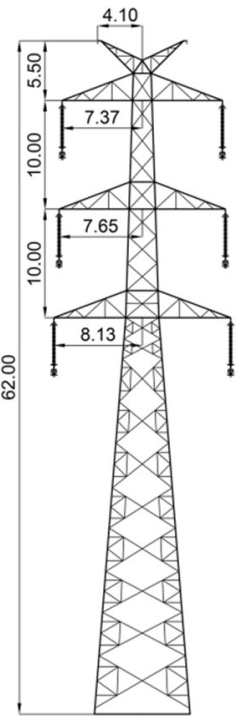

(b)

Figure 9. Configuration of a single circuit $400 \mathrm{kV}$ line (a) and a double circuit $400 \mathrm{kV}$ line (b).

In the single circuit line (Figure 9a), the phase conductors were assumed to be made as double conductor bundles $N=2,2 r=31.50 \mathrm{~mm}, b=400 \mathrm{~mm}$ and form a flat conductor 
configuration. Whereas in the double circuit line (Figure 9b) an assumption was made that the phase wires are made as triple conductor bundles $N=3,2 r=26.10 \mathrm{~mm}, b=400 \mathrm{~mm}$ forming a vertical conductor configuration. The insulator chains are $5.50 \mathrm{~m}$ long, except for the central phase chain of the single circuit line, for which the length is $5.25 \mathrm{~m}$. Moreover, span lengths of $450 \mathrm{~m}$, as well as equal phase and earth wire sags $f_{P}=f_{E}=13.5 \mathrm{~m}$ were also assumed.

\section{Analysis of Influence of Line Design Parameters on SE5 and SE1 Zone Widths}

The first step of the analysis lied in checking out whether or not it is possible to reduce the width of the single circuit line impact zone (Figure 9a) by increasing the wire height $h_{p}$ at tower from $23.5 \mathrm{~m}$ to $33.5 \mathrm{~m}$. Figure 10 shows the outer phase conductor profiles for selected heights $h_{p}$. The analysis considers both the case of a constant sag $f_{P}=f_{E}=13.5 \mathrm{~m}$ (Figure 10a) and variable sag $f_{P}=f_{E}=$ var situation at a constant minimum conductor-toground distance of $10 \mathrm{~m}$ (Figure 10b). Figure 11a,b illustrate the widths of zones $S_{E 5}$ and $S_{E 1}$ along the line span for a constant sag case, and Figure $11 \mathrm{c}, \mathrm{d}$ for a variable sag case. On the other hand, the dependence of zone widths $S_{E 5}=\max _{y}\left[s_{E 5}(y)\right]$ and $S_{E 1}=\max _{y}\left[s_{E 1}(y)\right]$ in a function of conductor height $h_{p}$ on tower is presented in Figure 12a.

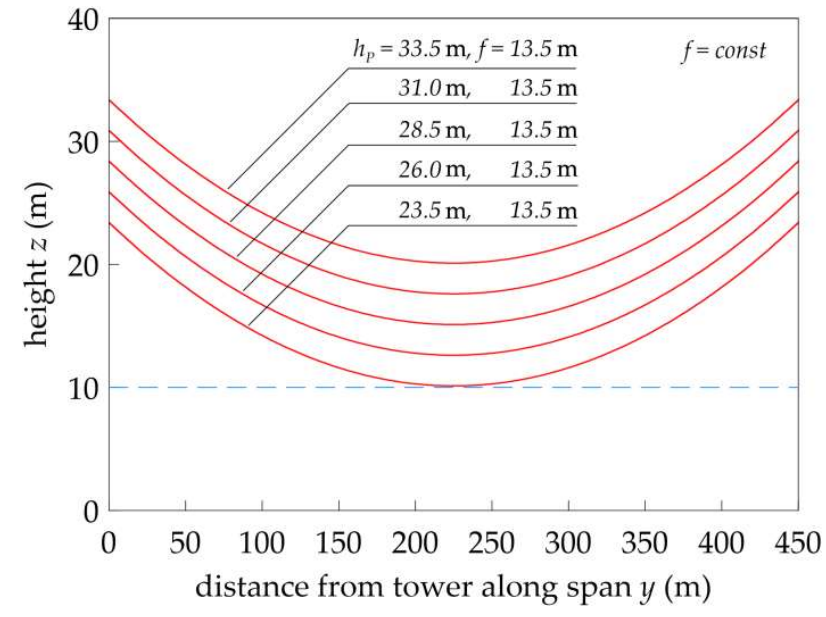

(a)

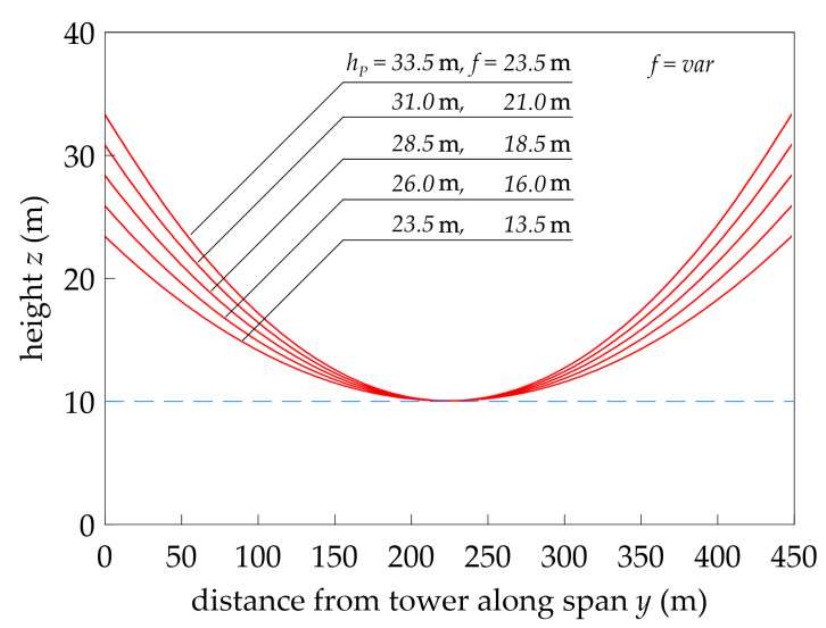

(b)

Figure 10. Conductor profiles of outer phases of a single circuit $400 \mathrm{kV}$ line: (a) constant sag $f_{P}=f_{E}=13.5 \mathrm{~m}$; (b) variable $\operatorname{sag} f_{P}=f_{E}=$ var.

Figure 12a shows that for $f=$ var, the zone widths do not depend on height $h_{p}$. For $f=$ const, the zone widths decrease with the increase of height $h_{p}$, zone $S_{E 1}$ is reduced by $0.7 \mathrm{~m}$ and zone $S_{E 5}$ by $1.2 \mathrm{~m}$. It should be noted that the increase of height $h_{p}$ has a negligible effect on the zone width reduction, but it has a significant effect on the noise level decrease. This has been illustrated in Figure $12 \mathrm{~b}$ showing a relationship of corona audible noise levels $L_{A 1}$ and $L_{A 5}$ at the boundary of $S_{E 1}$ and $S_{E 5}$ zones. The noise impact is reduced for $f=$ const. In this case, by increasing the height of conductors by $10 \mathrm{~m}$ the noise levels $L_{A 1}$ and $L_{A 5}$ are reduced by $2.1 \mathrm{~dB}$ and $3.3 \mathrm{~dB}$, respectively.

In the next step of the analysis, parameter $x_{P}$ was examined for different values and the effect it brings about. Two variants shown in Figure 13 were considered.

In the first variant (Figure 13a) an unchanged position $\left(x_{E}, \Delta h_{E}=\right.$ const) of earth wires is assumed to ensure a continuous lightning protection area. The zone shown in Figure 13a refers to the outermost phase and the inner phase conductor angles of lightning protection of $20^{\circ}$ and $45^{\circ}$, respectively. In the second variant (Figure 13b), it is assumed that the decrease of $x_{P}$ is accompanied by a simultaneous change in the position of earth wires $\left(x_{E}, \Delta h_{E}=v a r\right)$ to ensure constant values of the outermost phase and the inner phase conductor protection. 


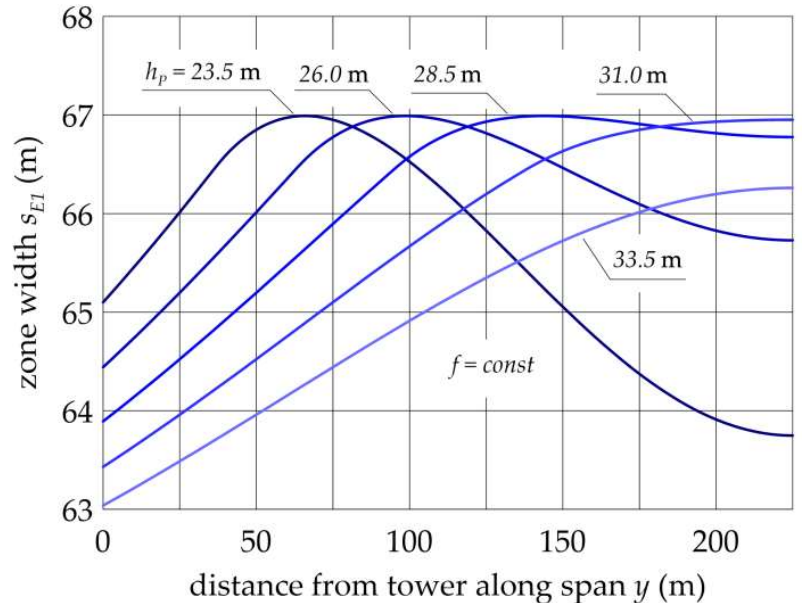

(a)

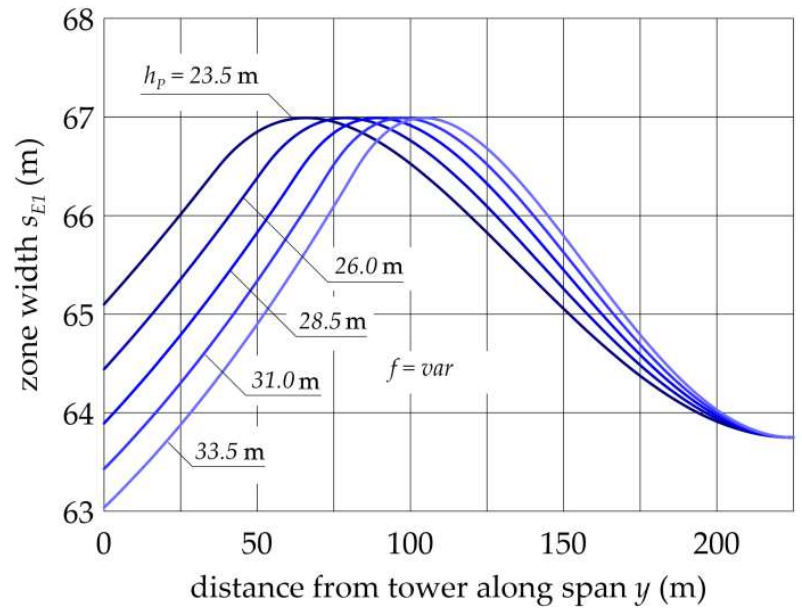

(c)

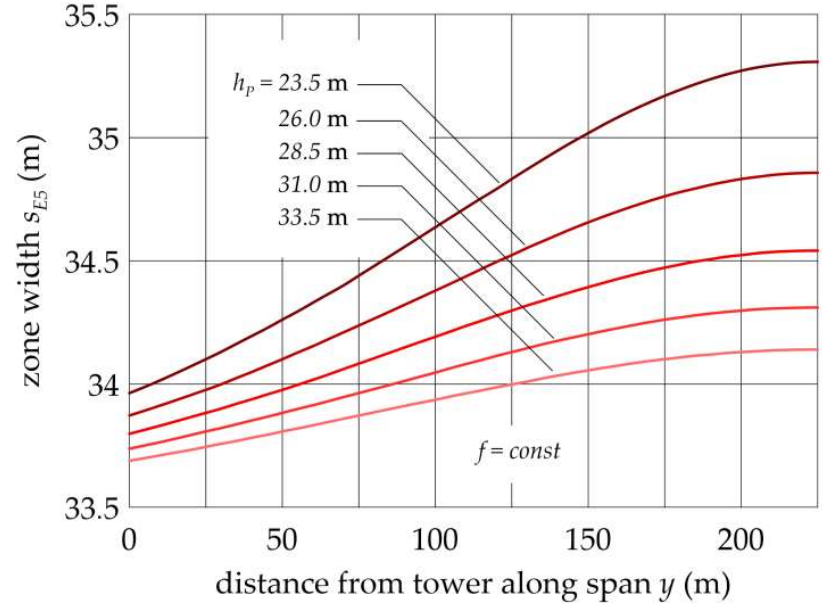

(b)

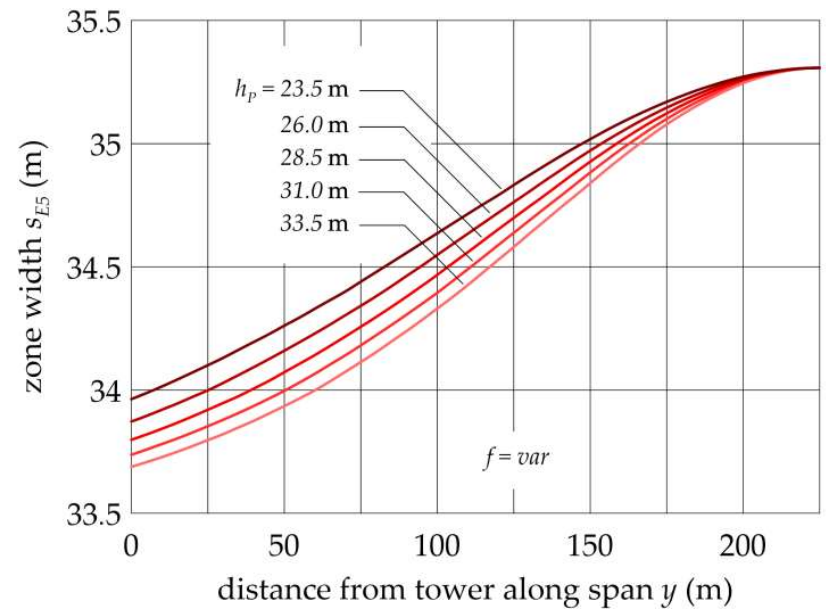

(d)

Figure 11. Variability of zone widths $s_{E 1}(\mathbf{a}, \mathbf{c})$ and $s_{E 5}(\mathbf{b}, \mathbf{d})$ along the span for constant $(\mathbf{a}, \mathbf{b})$ and variable $(\mathbf{c}, \mathbf{d})$ sag of conductors in a single circuit $400 \mathrm{kV}$ line.

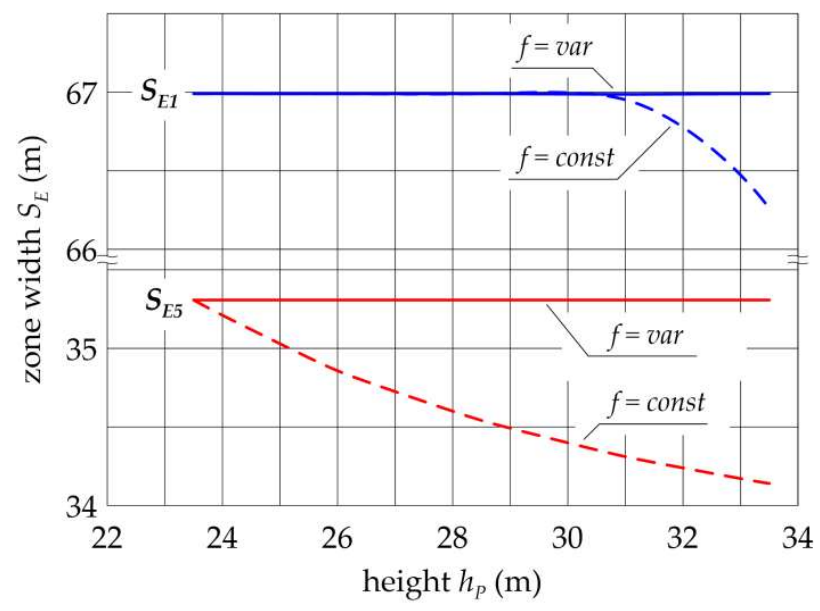

(a)

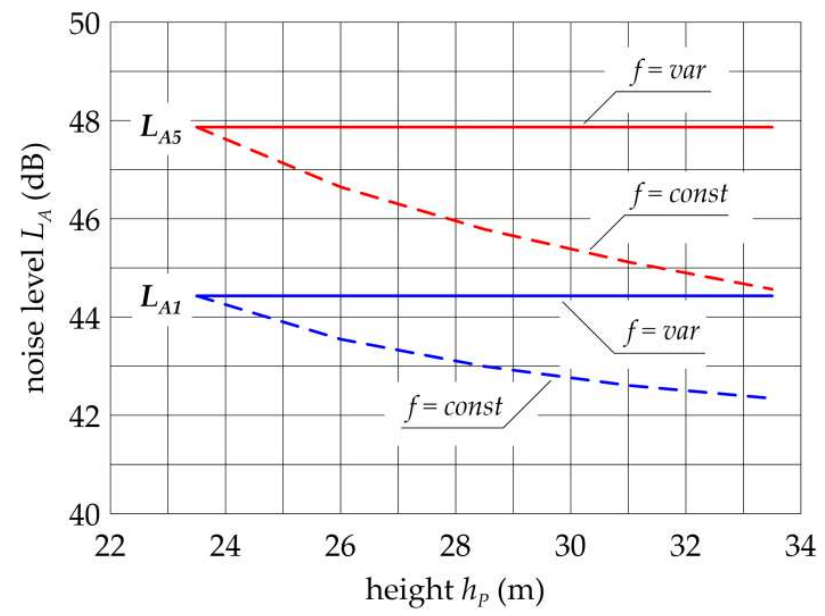

(b)

Figure 12. Influence of height $h_{P}$ on zone widths $S_{E 1}$ and $S_{E 5}(\mathbf{a})$ and corona audible noise level $L_{A 1}$ and $L_{A 5}$ on the boundary of zones $S_{E 1}$ and $S_{E 5}(\mathbf{b})$.

Figure 14a shows the width dependence of zones $S_{E 1}$ and $S_{E 5}$ as a function of distance $x_{P}$, and Figure $14 \mathrm{~b}$ visualizes the noise level dependence of $L_{A 1}$ and $L_{A 5}$. The variation of 
$x_{p}$ between $x_{P(\min )}=6 \mathrm{~m}$ and $x_{P(\max )}=11 \mathrm{~m}$ was considered. The value of $x_{P(\min )}$ results from normative requirements (e.g., [26]) regarding voltage-dependent clearance distances. On the other hand, the value of $x_{P(\max )}$ is limited by both technical and economic factors. The technical constraints arise from the increase in the tower bending moment with the growth of $x_{P}$. This, in turn, results in the higher cost of the tower, and consequently, the need to increase the mechanical strength of its structure and foundations. Another constraint of an economic nature is the increasing width of the right of way.

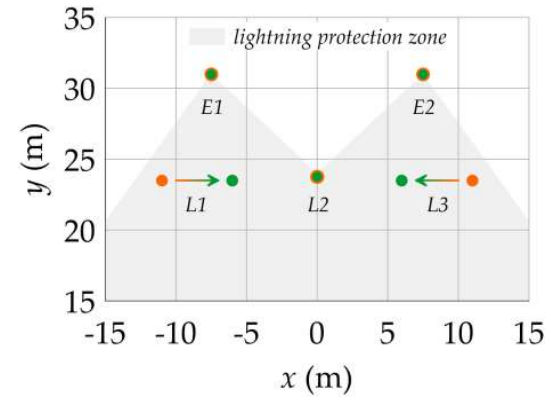

(a)

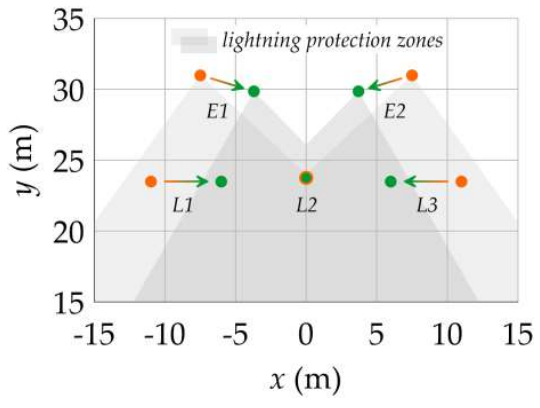

(b)

Figure 13. Range of parameter $x_{P}$ values in a single circuit $400 \mathrm{kV}$ line: (a) constant position of earth wires $x_{E}, \Delta h_{E}=$ const; $(\mathbf{b})$ variable position of earth wires $x_{E}, \Delta h_{E}=$ var.

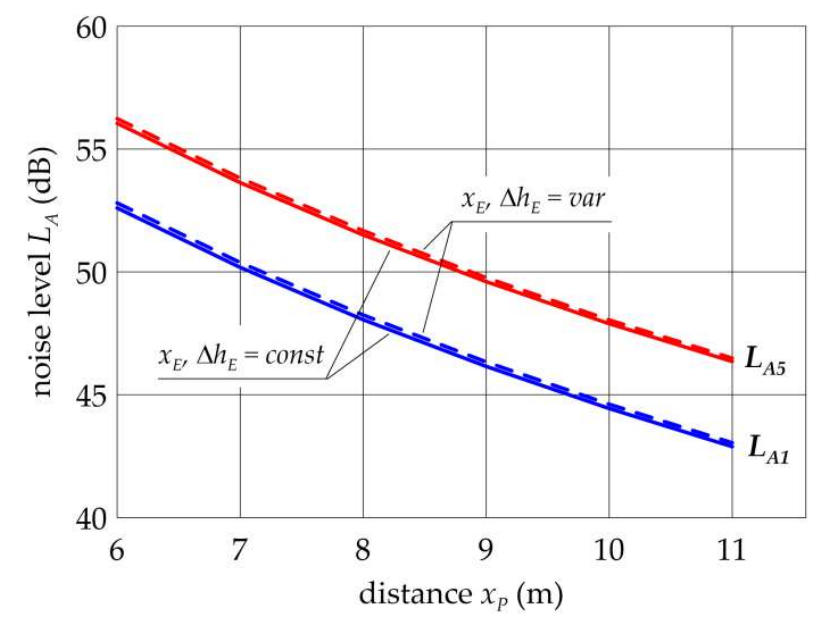

(a)

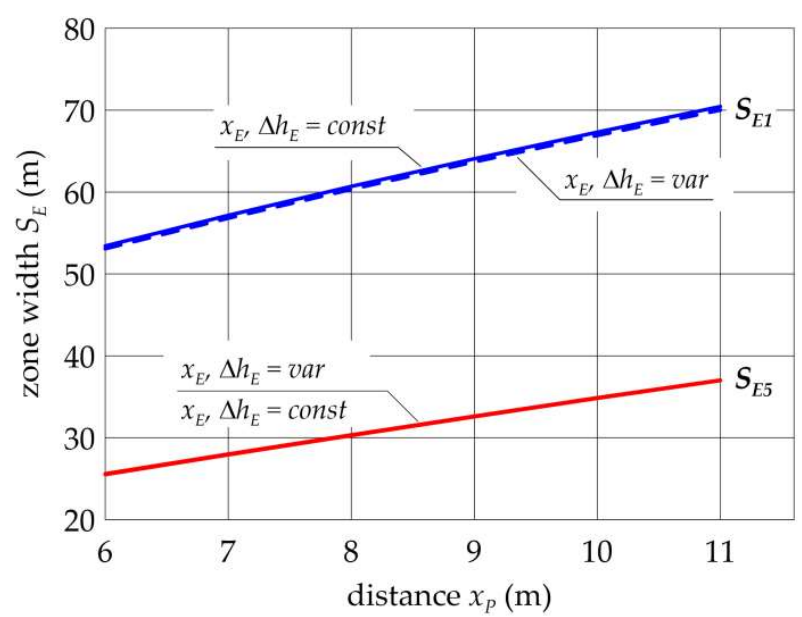

(b)

Figure 14. Influence of distance $x_{P}$ on zone widths $S_{E 1}$ and $S_{E 5}(\mathbf{a})$ and noise level $L_{A 1}$ and $L_{A 5}$ on the boundary of zones $S_{E 1}$ and $S_{E 5}(\mathbf{b})$.

Figure 14 shows that both zone widths and noise levels are virtually independent of the location of earth wires. With the decreasing distance $x_{P}$ from $11 \mathrm{~m}$ to $6 \mathrm{~m}$ zone width $S_{E 1}$ is narrowed by $17.0 \mathrm{~m}(24.1 \%)$, and zone $S_{E 5}$ by $11.4 \mathrm{~m}(30.9 \%)$. However, this reduction is accompanied by a significant increase in noise levels $L_{A 1}$ and $L_{A 5}$ by $9.8 \mathrm{~dB}$.

The range of parameter $x_{P}$ values can be broadened in the analyzed $400 \mathrm{kV}$ line below the lower boundary $x_{P(\mathrm{~min})}=6 \mathrm{~m}$ if the phase conductor configuration is changed from flat to triangular. Two variants of this reconfiguration, involving the increase the height of the central phase by $\Delta h_{P}=0 \div 8 \mathrm{~m}$, are presented in Figure 15 . The first variant assumed a simultaneous decrease of parameter $x_{P}$ from $x_{P(\max )}=11 \mathrm{~m}$ to $x_{P(\min )}=3 \mathrm{~m}$ (Figure 15a). In the second variant, a constant value of $x_{P}=11 \mathrm{~m}$ is assumed for the outermost phase (Figure 15b).

Increasing the height of the central phase conductor while decreasing the distance of the outermost phase conductors $\left(x_{P}=\right.$ var $)$, significantly reduces the width of the electric field impact zones (Figure 16a). In the analyzed $400 \mathrm{kV}$ line, a narrowing of the zone width 
$S_{E 1}$ by $31.2 \mathrm{~m}(44.2 \%)$, and zone $S_{E 5}$ by $18.3 \mathrm{~m}(49.4 \%)$ is achieved. However, this reduction is accompanied by a significant increase in noise levels $L_{A 1}$ and $L_{A 5}$ by $10.1 \mathrm{~dB}$ and $9.7 \mathrm{~dB}$, respectively (Figure 16b). If the position of the outermost phase conductors remains the same $\left(x_{P}=v a r\right)$, the change of distance $\Delta h_{P}$ does not affect zone widths $S_{E 1}$ and $S_{E 5}$, though reduces noise levels $L_{A 1}$ and $L_{A 5}$ by $2.8 \mathrm{~dB}$.

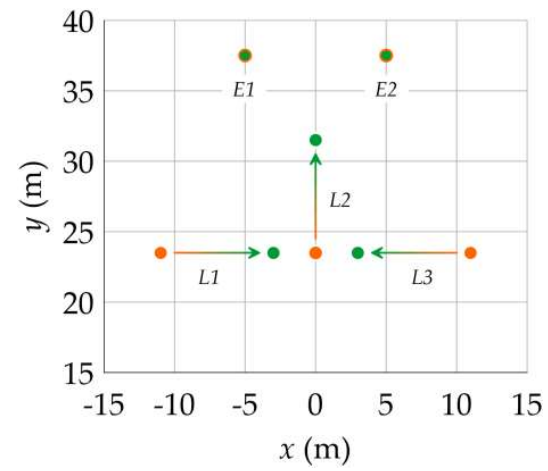

(a)

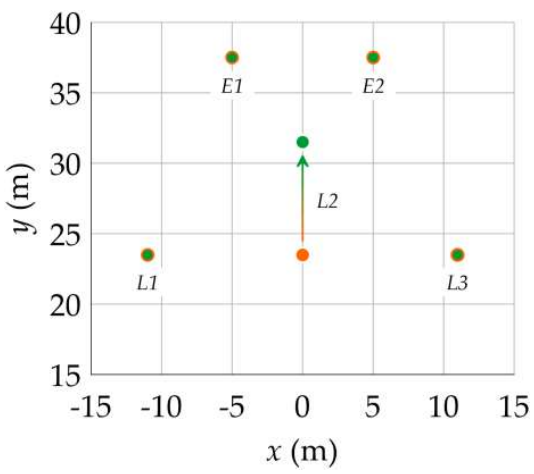

(b)

Figure 15. Reconfiguration of flat conductor configuration to triangular conductor configuration in a single circuit $400 \mathrm{kV}$ line: (a) variable position of the outermost phase conductors $x_{P}=$ var; (b) constant position of outermost phase conductors $x_{P}=$ const.

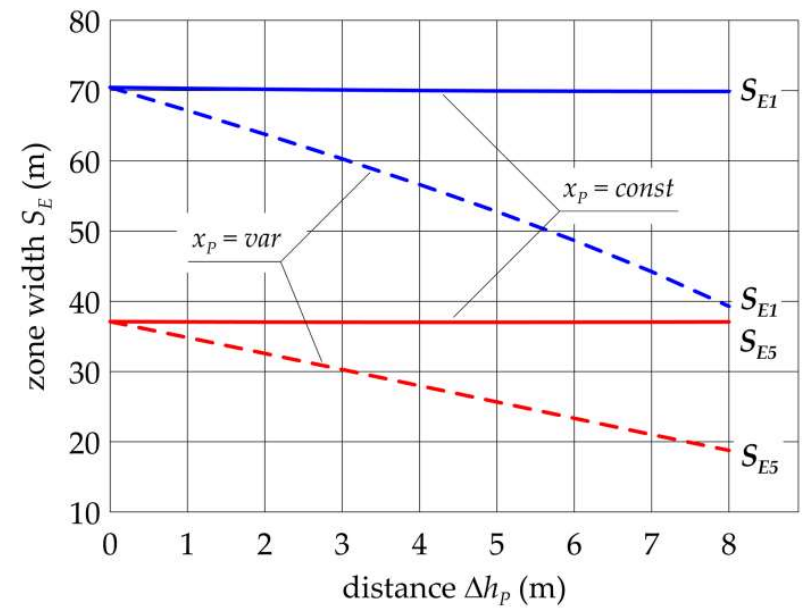

(a)

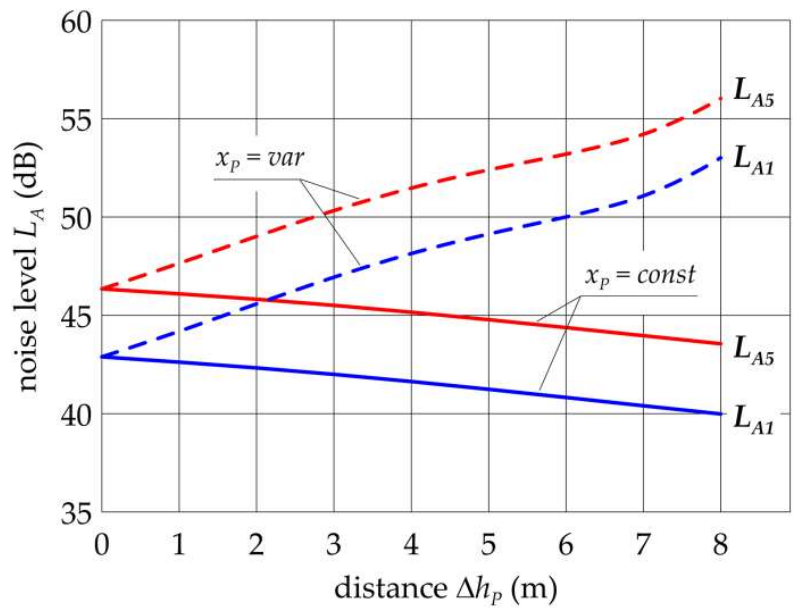

(b)

Figure 16. Influence of distance $h_{P}$ on zone widths $S_{E 1}$ and $S_{E 5}(\mathbf{a})$ and noise levels $L_{A 1}$ and $L_{A 5}$ on the boundary of zones $S_{E 1}$ and $S_{E 5}(\mathbf{b})$.

The considerations presented so far concentrated on a $400 \mathrm{kV}$ line in which phase conductors consisted of two-sub-conductor bundles with the following parameters (Figure 8c): $N=2,2 r=31.50 \mathrm{~mm}, b=400 \mathrm{~mm}, \alpha=0^{\circ}$. The type of the applied bundle conductors affects the electromagnetic and noise impact of the power lines. Further studies of the case shown in Figure 15a were carried out to analyze this influence. Two options were considered: (i) changing number $N$ of sub-conductors in the bundle, (ii) changing distance $b$ between sub-conductors in the bundle.

In the first variant, the tests were carried out for three types of bundled conductors (Figure 17a): (i) $N=2\left(2 r=31.50 \mathrm{~mm}, b=400 \mathrm{~mm}, \alpha=0^{\circ}\right)$, (ii) $N=3(2 r=26.10 \mathrm{~mm}$, $\left.b=400 \mathrm{~mm}, \alpha=30^{\circ}\right), N=4\left(2 r=26.10 \mathrm{~mm}, b=400 \mathrm{~mm}, \alpha=45^{\circ}\right)$. In the second variant, the tests were performed for $N=3$ conductors, assuming a variation of distance $b$ from $50 \mathrm{~mm}$ to $600 \mathrm{~mm}$ (Figure 17b). 


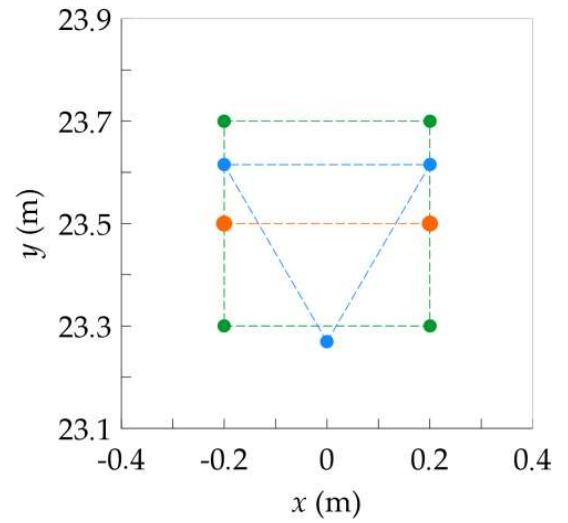

(a)

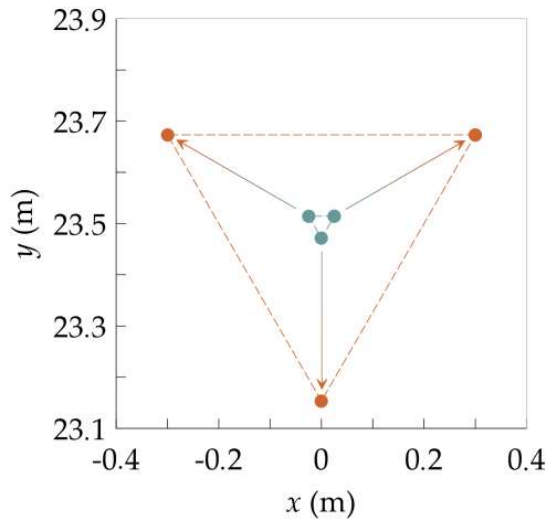

(b)

Figure 17. Analyzed bundled conductors: (a) changed number of conductors $N$; (b) change of distance $b$.

The increasing number of $N$ wires in a bundle results in a broader width of zones $S_{E 1}$ and $S_{E 5}$ (Figure 18a). For $\Delta h_{p}=0$ (flat configuration) the triple bundle $(N=3)$ increases the zone width $S_{E 1}$ by $3.0 \mathrm{~m}(4.3 \%)$ and zone $S_{E 5}$ by $1.3 \mathrm{~m}(3.5 \%)$, as compared to the zone widths of double conductor lines $(N=2)$. For the quadruple conductor bundle $(N=4)$, these values are even higher and are $5.7 \mathrm{~m}(8.1 \%)$ and $2.5 \mathrm{~m}(6.7 \%)$, respectively. For $\Delta h_{p}=8 \mathrm{~m}$ the triple conductor bundle $(N=3)$ makes zones $S_{E 1}$ and $S_{E 5}$ wider by $2.3 \mathrm{~m}$ $(5.8 \%)$ and by $0.9 \mathrm{~m}(5.0 \%)$, respectively. In the case of a quadruple conductor bundle $(N=4)$, these values are $4.4 \mathrm{~m}(11.1 \%)$ and $1.8 \mathrm{~m}(9.7 \%)$, respectively.

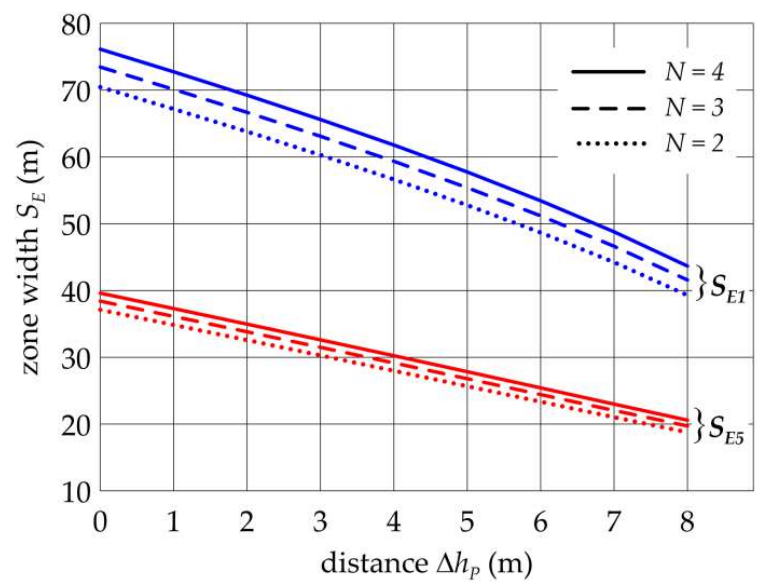

(a)

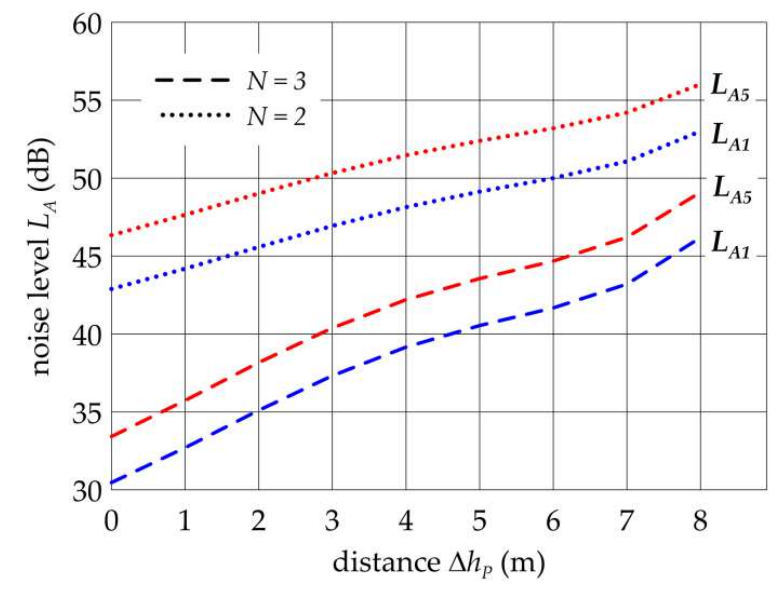

(b)

Figure 18. Influence of number $N$ of sub-conductors in a bundle and distance $\Delta h_{P}$ on zone widths $S_{E 1}, S_{E 5}$ (a) and noise levels $L_{A 1}, L_{A 5}(\mathbf{b})$.

Although the increased number $N$ of conductors in a bundle is associated with an adverse effect of a bigger electromagnetic impact, a significant reduction of noise impacts is achieved (Figure 18b). When a three conductor bundle $(N=3)$ is used, the noise levels $L_{A 1}$ and $L_{A 5}$ decrease by ca. $12.5 \mathrm{~dB}$ for $\Delta h_{p}=0 \mathrm{~m}$ and by about $6.9 \mathrm{~dB}$ for about $\Delta h_{p}=8 \mathrm{~m}$ as compared to a double conductor bundle line $(N=2)$. In the case of a quadruple conductor bundle line $(N=4)$, the electric field strength at the wire surface is below the initial corona, and no noise impact is observed.

The sub-conductor distance $b$ in the bundle affects zone widths $S_{E 1}$ and $S_{E 5}$ (Figure 19a). In the considered range of distance $b$ from 50 to $600 \mathrm{~mm}$ the zone width $S_{E 1}$ increases by $9.4 \mathrm{~m}(15.1 \%)$ and $S_{E 5}$ by $4.0 \mathrm{~m}(11.9 \%)$. The effect of parameter $b$ on the noise level is complex (Figure 19b). Initially the values of $L_{A 1}$ and $L_{A 5}$ decrease with the increase of $b$ 
and for $b \approx 150 \mathrm{~mm}$ reach the lowest values $19.7 \mathrm{~dB}$ and $22.7 \mathrm{~dB}$. A further increase of $b$ results in an increase of the noise level values. However, in practice, the problem of choosing the optimum value of distance $b$ is complex. Many other factors influence the choice, primarily the number of sub-conductors, in the bundle climatic conditions and the resulting need to prevent excessive icing as well as the effects of sub-span vibrations between conductor spacers. For these reasons, distance values $b$ are usually equal to 300-500 mm.

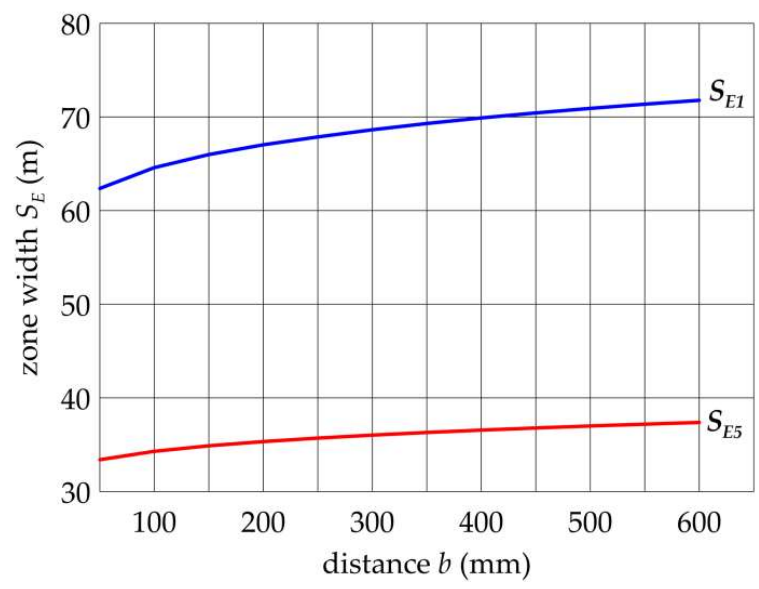

(a)

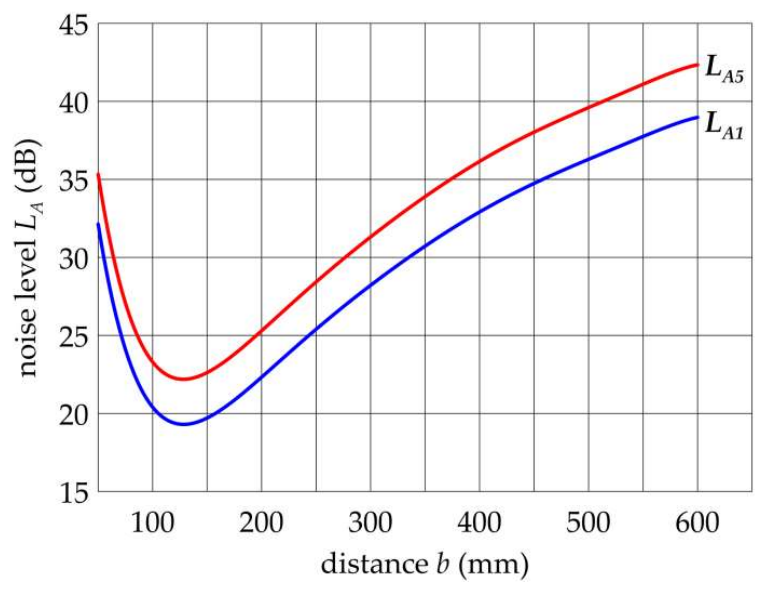

(b)

Figure 19. Influence of sub-conductor distance $b$ in a bundle on zone widths $S_{E 1}$ and $S_{E 5}$ (a) and noise level $L_{A 1}$ and $L_{A 5}$ on the boundary of zones $S_{E 1}$ and $S_{E 5}(\mathbf{b})$.

Conclusions resulting from the analyses of the single circuit lines are also valid for double circuit lines as far as qualitative aspects are concerned. This applies first of all to the impact of $x_{p}$ parameter, which in the case of the double circuit lines is the phase conductor horizontal distance to the axis, and the effect of the phase conductors design. Figure 20 shows the range of changes of the phase conductors on a double circuit $400 \mathrm{kV}$ line adopted for the analysis from Figure $9 \mathrm{~b}$. A constant location of earth wires was assumed $x_{E}$, $\Delta h_{E}=$ const and a constant distance $\Delta h_{P}=$ const phase conductors. Figure 21a shows the zone width relationships of $S_{E 1}$ and $S_{E 5}$ in a function of distance $x_{P}$, and in Figure 21b noise levels $L_{A 1}$ and $L_{A 5}$. Consideration was given to the change of $x_{p}$ from $x_{P(\min )}=4.5 \mathrm{~m}$ to $x_{P(\max )}=8.5 \mathrm{~m}$. As in a single circuit line, the value of $x_{P(\min )}$ results from normative requirements, and the value of $x_{P(\max )}$ is limited by technical and economic constraints.

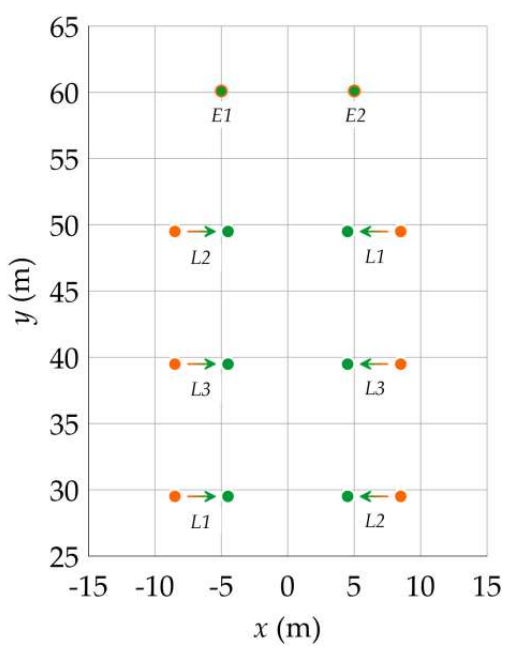

Figure 20. Range of parameter $x_{P}$ on a double circuit $400 \mathrm{kV}$ line-constant position of earth wires $x_{E}, \Delta h_{E}=$ const and a constant vertical distance $\Delta h_{P}=$ const. 


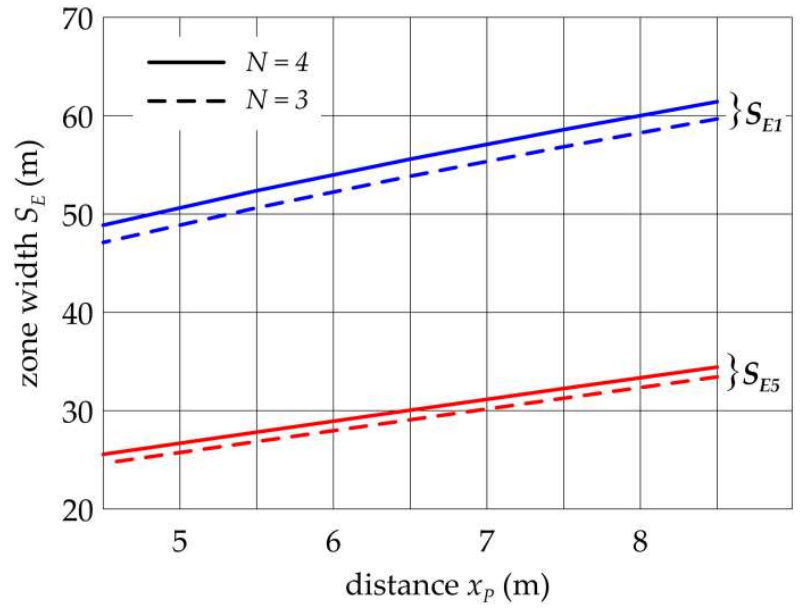

(a)

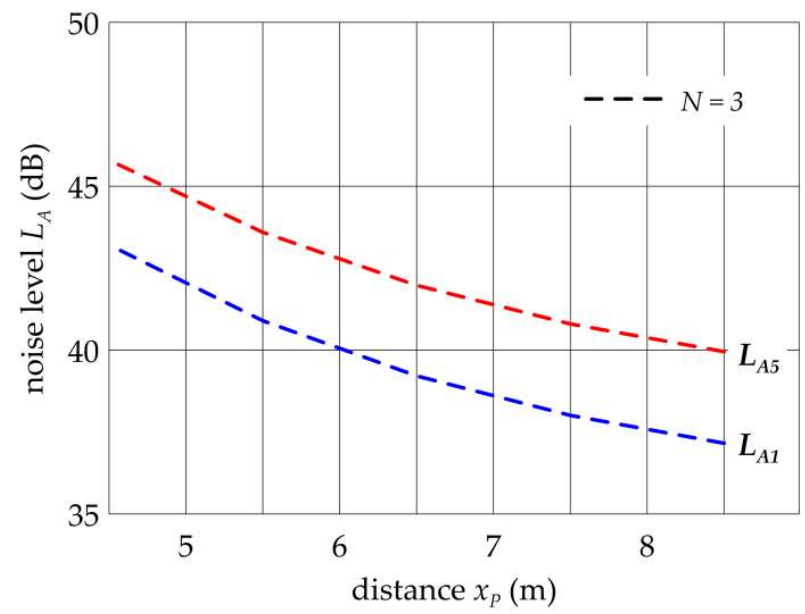

(b)

Figure 21. Influence of distance $x_{P}$ on zones width $S_{E 1}$ and $S_{E 5}(\mathbf{a})$ and noise level $L_{A 1}$ and $L_{A 5}$ on the boundary of zones $S_{E 1}$ and $S_{E 5}$ for a double circuit $400 \mathrm{kV}$ line (b).

Figure 21 shows that regardless of the number $N$ of wires in the bundle, with decreasing distance $x_{P}$ from $8.5 \mathrm{~m}$ to $4.5 \mathrm{~m}$ zone width $S_{E 1}$ is narrowed by about $12.6 \mathrm{~m}(20.7 \%)$, and zone $S_{E 5}$ by about $8.8 \mathrm{~m} \mathrm{(26.0 \% ).} \mathrm{Analogous} \mathrm{to} \mathrm{the} \mathrm{single} \mathrm{circuit} \mathrm{line,} \mathrm{the} \mathrm{reduction}$ in zone width is accompanied by an increase of noise levels $L_{A 1}$ and $L_{A 5}$ by $5.9 \mathrm{~dB}$ for a triple conductor bundle line. In the case of a four-conductor bundle, no noise emission is observed.

Characteristically for the double circuit lines, the electromagnetic and noise impacts depend on the phase conductor configurations in overhead line circuits. Figure 22 presents four variants of such configurations, for which zone widths $S_{E 1}, S_{E 5}$ and noise levels $L_{A 1}$, $L_{A 5}$ are presented in Figure 23.
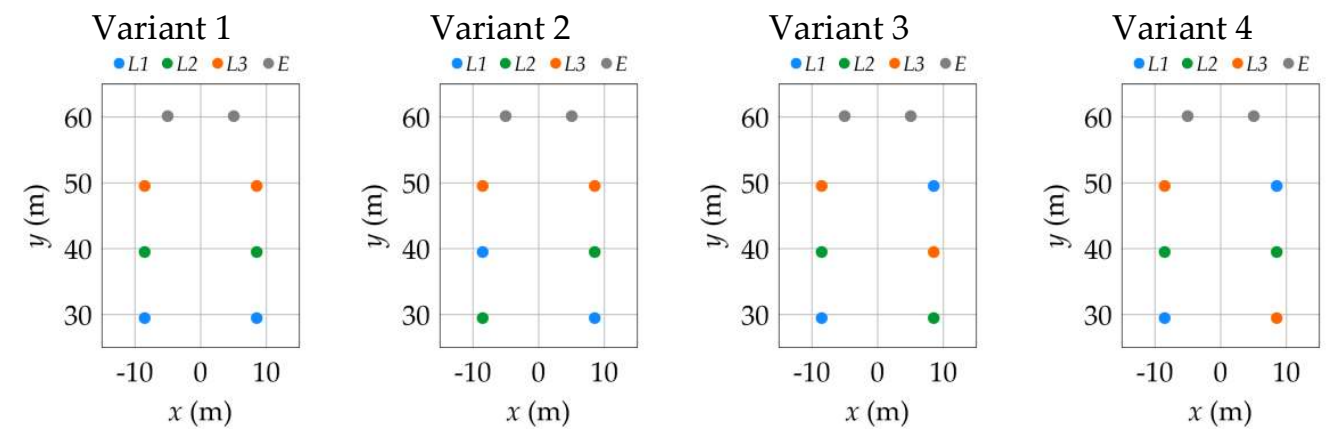

Figure 22. Considered variants of phase conductor configurations in a double circuit $400 \mathrm{kV}$ line.

The phase conductor configuration significantly affects zone width $S_{E 1}$ (Figure 23a). The zone was broadest in Variant $1(69.1 \mathrm{~m})$ and the narrowest in Variant $4(59.7 \mathrm{~m})$. Shifting from the phase conductor configuration in Variant 1 to the phase conductor configuration in Variant 4 results in a reduction of zone $S_{E 1}$ by $13.6 \%$. The reduction of zone $S_{E 5}$ is much smaller and is $5.9 \%$. Unfortunately, this method of reducing zone widths is accompanied by a significant increase of noise levels $L_{A 1}, L_{A 5}$, which in the case of Variant 4 are about $4 \mathrm{~dB}$ higher than in Variant 1 (Figure 23b). 


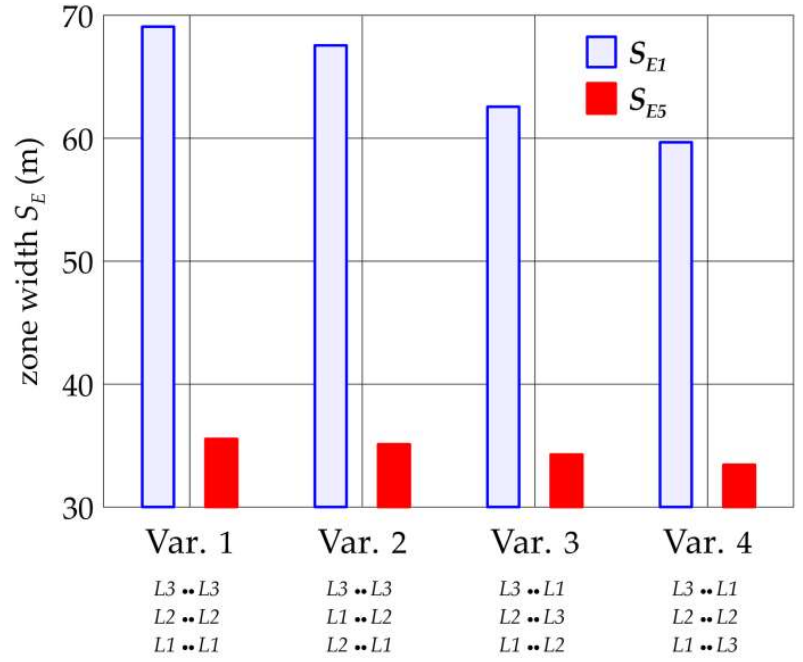

(a)

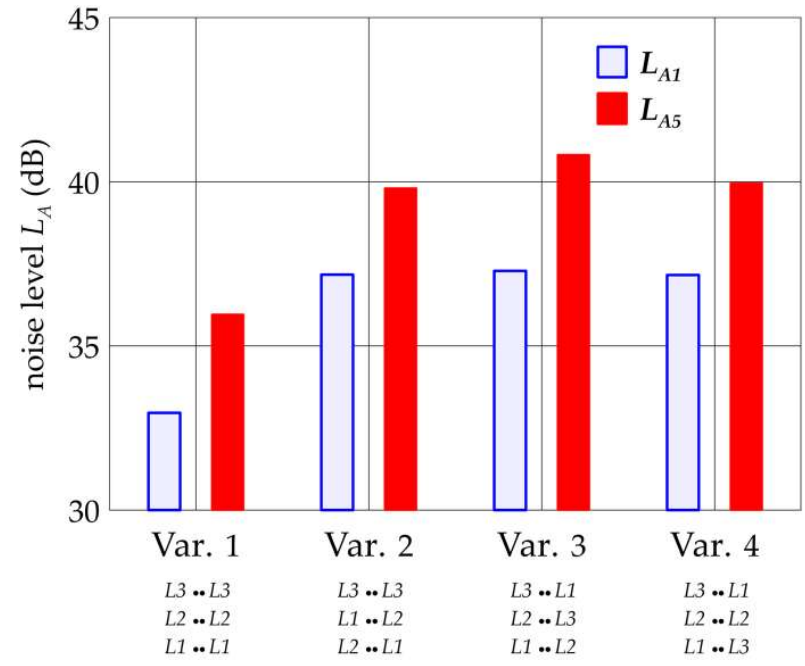

(b)

Figure 23. Influence of the phase conductor configuration in a double circuit $400 \mathrm{kV}$ line on zone widths $S_{E 1}$ and $S_{E 5}$ (a) and noise level $L_{A 1}$ and $L_{A 5}$ on the boundary of zones $S_{E 1}$ and $S_{E 5}(\mathbf{b})$.

\section{Conclusions}

It follows from the research that $x_{p}$ is the main parameter determining the width of the electric field influence zone. By decreasing its value we may reduce the width of the influence zones even by about $21 \% \div 31 \%$ in both single and double circuit power lines. In single circuit power lines, it is also parameter $\Delta h_{p}$ which significantly influences the zone width. By increasing its value, a further reduction in $x_{p}$ value can be achieved. On the whole, a $42 \% \div 50 \%$ reduction in the electric field influence zones can be obtained. As far as the environmental impact is concerned, the triangular phase conductor configuration turns out to be definitely more beneficial in the case of single circuit power lines than the flat one.

A slight effect on reducing the impact zones is achieved by an increase in the height of phase conductors $h_{p}$ on a tower. This happens only when the distance between phase conductors and the ground is increased along the entire span. On the other hand, a change in height $h_{p}$ at a constant distance of phase conductors from the ground in the middle of the span does not affect the width of the electric field influence zone.

The research has shown that the order of phases in particular circuits in double circuit power lines has a significant effect on the width of electric field influence zones. The biggest differences in their width reach over ten percent.

Unfortunately, these methods of limiting the electric field influence zones are accompanied by an increase in the corona audible noise level at the border of these zones (in extreme cases even by about $10 \mathrm{~dB}$ ). Thus, the possibility of reducing the electric field influence zones may be conditioned by the regulations on noise intensity limits in a given area.

Unlike phase wires, the location of earth wires almost does not affect the width of electric field zones.

Research has shown that the increased number of conductors in a bundle results in a slight broadening of electric field influence zones. However, a decreased distance between the conductors in the bundle contributes to a dozen percent reduction of the width of the influence zones. It should be taken into account that the main purpose of using conductor bundles in high-voltage lines is to reduce the negative effects of corona, including noise emission. Therefore, the parameters of conductor bundles are usually selected based on other factors than the width of electric field influence zones.

Studies have shown that the proposed constructional changes can significantly reduce the width of the line's electromagnetic impact zones. However, an increase in line construction costs must be taken into account. A precise determination of the costs of the proposed 
solutions is possible only for specific line designs. The authors' design experience shows that the increase can be within a wide range (from a few $\%$ to even $40 \%$ ). The presented estimates do not include the cost of acquiring an area to build the line. It should be noted that the reduction in land acquisition costs resulting from a reduction in the width of the impact zone may, in some cases, be more than the increase in construction costs resulting from a change in the line's design.

The paper shows that the reduction in the negative environmental impact of power line influence zones is a complex issue. The originality of the solution to this problem lies in the use of complementary and experimentally verified author's models of electric field and corona audible noise generated by power lines. The obtained results are valid not only for $400 \mathrm{kV}$ lines; they also establish trends for the design and construction of high voltage transmission lines of other rated voltages (above $100 \mathrm{kV}$ ). Attention should be also paid to the fact that the reduction of the environmental impact of power infrastructure is an element of power energy transition processes currently taking place.

Author Contributions: Conceptualization, W.N. and R.T.; methodology, W.N., R.T. and T.W.; software, K.K., W.N., R.T. and W.S.; validation, K.K., W.N., R.T., W.S. and T.W.; formal analysis, W.N., R.T. and T.W.; investigation, K.K., W.N. and R.T.; writing-original draft preparation, K.K., W.N., R.T., W.S. and T.W.; writing-review and editing, R.T.; visualization, W.N. and R.T.; supervision, R.T. All authors have read and agreed to the published version of the manuscript.

Funding: This research received no external funding.

Institutional Review Board Statement: Not applicable.

Informed Consent Statement: Not applicable.

Conflicts of Interest: The authors declare no conflict of interest.

\section{References}

1. International Commission On Non-Ionizing Radiation Protection. ICNIRP Guidelines for limiting exposure to time-varying electric, magnetic and electromagnetic field (up to $300 \mathrm{GHz}$ ). Health Phys. 1998, 74, 494-522.

2. Council of the European Union. Council Recommendation of 12 July 1999 on the limitation of exposure of the general public to electromagnetic fields (0 Hz to $300 \mathrm{GHz})$. Off. J. Eur. Communities 1999, 42, 59-70.

3. National Institute for Public Health and the Environment. Comparison of International Policies on Electromagnetic Fields (Power Frequency and Radiofrequency Fields); National Institute for Public Health and the Environment, RIVM: Bilthoven, The Netherlands, 2017.

4. International Commission On Non-Ionizing Radiation Protection. ICNIRP Guidelines for limiting exposure to time-varying electric and magnetic fields (1 Hz to $100 \mathrm{kHz}$ ). Health Phys. 2010, 99, 818-836. [CrossRef] [PubMed]

5. World Health Organization. Guidelines for Community Noise; World Health Organization: Geneva, Switzerland, 1999.

6. World Health Organization. Environmental Noise Guidelines for the European Region; World Health Organization Regional Office for Europe: Copenhagen, Denmark, 2018.

7. The European Parliament and of the Council. Directive 2002/49/EC of the European Parliament and of the Council of 25 June 2002 relating to the assessment and management of environmental noise. Off. J. Eur. Communities 2002, 189, 12-26.

8. International Council on Large Electric Systems. Corona Noise Comparison of the Standard and Surface Treated Conductors Obtained with Monitoring of the Newly Erected 400 kV Line and with Corona Testing in High-Voltage Laboratory; CIGRE: Paris, France, 2016.

9. Engel, Z.; Wszołek, T. Audible noise of transmission lines caused by the corona effect: Analysis, modeling, prediction. Appl. Acoustic. 1996, 47, 149-163. [CrossRef]

10. Griffiths, D.J. Introductions to Electrodynamics, 4th ed.; Cambridge University Press: Cambridge, UK, 2017. [CrossRef]

11. El Dein, A.Z. Calculation of the electric field around the tower of the overhead lines. IEEE Trans. Power Del. 2014, 29, 899-907. [CrossRef]

12. Li, Q.; Rowland, S.M.; Shuttleworth, R. Calculating the surface potential gradient of overhead line conductors. IEEE Trans. Power Del. 2015, 30, 43-52. [CrossRef]

13. Wang, R.; Tian, J.; Wu, F.; Zhang, Z.; Liu, H. PSO/GA Combined with Charge Simulation Method for the Electric Field under Transmission Lines in 3D Calculation Model. Electronics 2019, 8, 1140. [CrossRef]

14. Grbić, M.; Pavlović, A. Determining the zone of influence of transmission overhead power lines from the aspect of non-ionizing radiation. RAD Conf. Proc. 2018, 3, 52-57. [CrossRef]

15. El Dein, A.Z.; Wahab, M.A.A.; Hamada, M.M.; Emmary, T.H. The effects of the span configurations and conductor sag on the electric-field distribution under overhead transmission lines. IEEE Trans. Power Del. 2010, 4, 2891-2902. [CrossRef]

16. Rácz, L.; Németh, B. Dynamic Line Rating-An Effective Method to Increase the Safety of Power Lines. Appl. Sci. 2021, 11, 492. [CrossRef] 
17. Salari, J.C.; Mpalantinos, A.; Silva, J.I. Comparative analysis of 2-and 3-D methods for computing electric and magnetic fields generated by overhead transmission lines. IEEE Trans. Power Del. 2009, 1, 338-344. [CrossRef]

18. Liang, Z.; Jiang, Y.; Hong, J. Influence of complex terrains on electric field under overhead lines. In Proceedings of the 5th International Conference on Information Science and Control Engineering (ICISCE), Zhengzhou, China, 20-22 July 2018; IEEE Computer Society: Los Alamitos, CA, USA, 2018. [CrossRef]

19. International Electrotechnical Commission. IEC 61672-1:2013. Electroacoustics-Sound Level Meters-Part. 1: Specification, 2nd ed.; International Electrotechnical Commission: Geneva, Switzerland, 2013.

20. International Organization for Standardization Technical Committee ISO/TC 43/SC 1 Noise. ISO 1996-1:2016. AcousticsDescription, Measurement and Assessment of Environmental Noise-Part. 1: Basic Quantities and Assessment Procedures; International Organization for Standardization: Geneva, Switzerland, 2016.

21. International Organization for Standardization Technical Committee ISO/TC 43/SC 1 Noise. ISO 1996-2:2017. AcousticsDescription, Measurement and Assessment of Environmental Noise-Part. 2: Determination of Sound Pressure Levels; International Organization for Standardization: Geneva, Switzerland, 2017.

22. Chartier, V.L.; Sterans, R.D. Formulas for predicting audible noise from overhead high voltage AC and DC lines. IEEE Trans. Power App. Syst. 1981, 1, 121-129. [CrossRef]

23. Doyle, J.R.; LaForest, J.J.; Lauber, T.S. Electrical characteristics of EHV-UHV conductors configurations and circuit. In Transmission Line Reference Book 345 kV and Above, 2nd ed.; LaForest, J.J., Ed.; Electric Power Research Institute Inc.: Palo Alto, CA, USA, 1982; pp. 63-167.

24. International Council on Large Electric Systems, Working Group 36.01. TB 020. Interferences Produced by Corona Effect of Electric Systems; CIGRE: Paris, France, 1974.

25. International Council on Large Electric Systems, Working Group 36.01. TB 061. Addenum to CIGRE Document No. 20. Interferences Produced by Corona Effect of Electric Systems; CIGRE: Paris, France, 1996.

26. European Committee for Electrotechnical Standardization. EN-50341-1:2012 Overhead Electrical Lines Exceeding AC 1 kVPart. 1: General Requirements-Common Specifications; CENELEC European Committee for Electrotechnical Standardization: Brussels, Belgium, 2012. 